\title{
O RECENTE PROCESSO MIGRATÓRIO INTERNO BRASILEIRO E SEUS DETERMINANTES
}

VIVIANE MENDONÇA PEREIRA

Bacharel em Ciências Econômicas

Orientadora: Profa. Dra. ANA LÚCIA KASSOUF

Dissertação apresentada à Escola Superior de Agricultura "Luiz de Queiroz”, Universidade de São Paulo, para a obtenção de título de Mestre em Ciências, Área de Concentração: Economia Aplicada.

PIRACICABA

Estado de São Paulo - Brasil

Dezembro de 2000 
Dados Internacionais de Catalogação na Publicação (CIP)

DIVISĀO DE BIBLIOTECA E DOCUMENTAÇĀO - Campus "Luiz de Queiroz"/USP

\section{Pereira, Viviane Mendonça}

O recente processo migratório intemo brasileiro e seus determinantes / Viviane Mendonça Pereira / Viviane Mendonça Pereira. - - Piracicaba, 2000.

$62 \mathrm{p}$.

Dissertação (mestrado) - - Escola Superior de Agricultura Luiz de Queiroz, 2000. Bibliografia.

1. Cor 2. Determinante 3. Educação 4. Idade 5. Migração intema 6. Renda familiar 7. Sexo I. Título

CDD 325.81 
Dedico

Aos meus pais, Mateus e Maria Izabel, aos meus irmãos Rodrigo e Netinho e ao meu noivo José. 


\section{AGRADECIMENTOS}

Agradeço a minha orientadora Ana Lúcia Kassouf, aos professores Zilda, Míriam e Fernando Peres que contribuíram de maneira relevante para a elaboração deste trabalho. Agradeço também a Maielli pela colaboração e a todos os amigos que conquistei neste período e que foram importantes na concretização deste passo, especialmente à Cassiana, Chíntia e Paula.

Agradeço de forma especial a minha família, que apesar de longe sempre esteve comigo e ao meu noivo José pelo apoio e força nos momentos que mais precisei. 


\section{ÍNDICE}

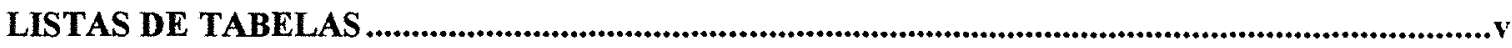

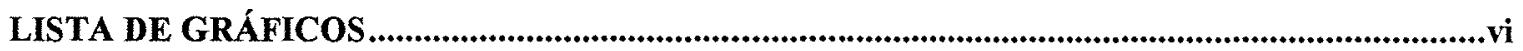

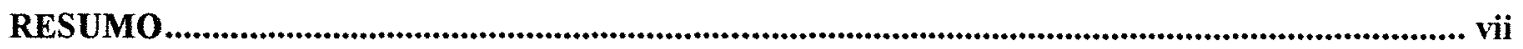

SUMMARY

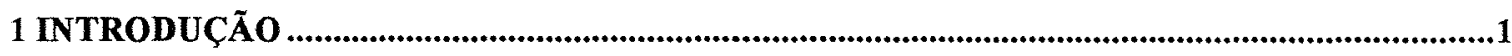

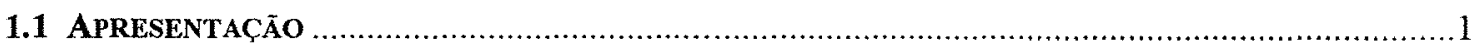

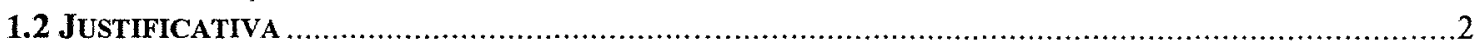

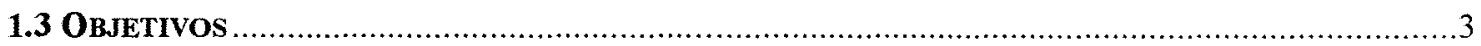

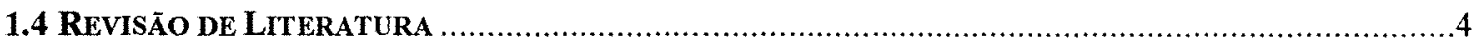

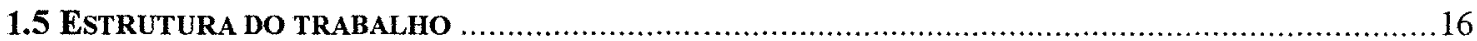

2 CONSIDERAÇÕES E ESTATÍSTICAS BÁSICAS SOBRE O PROCESSO MIGRATÓRIO

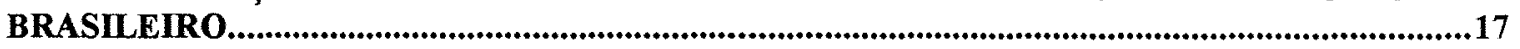

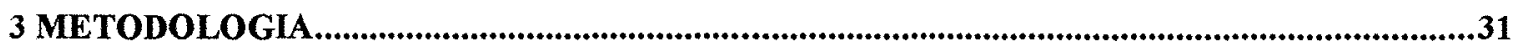

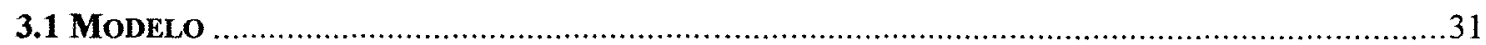

3.2 DADOS

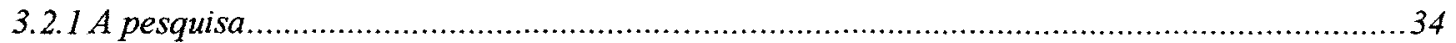

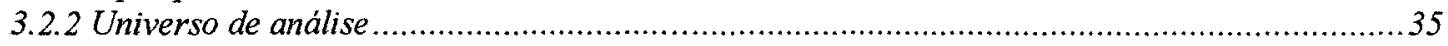

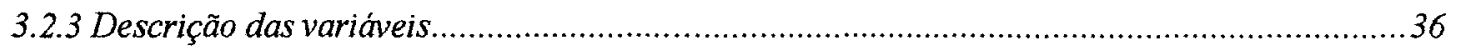

4 RESULTADOS DO MODELO ECONOMÉTRICO.......................................................................41

OS DETERMINANTES DOS MOVIMENTOS MIGRATÓRIOS INTERNOS NO BRASIL .....................................41

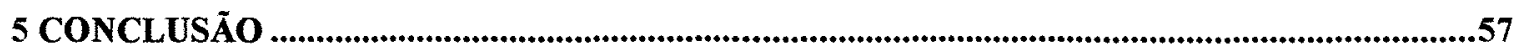

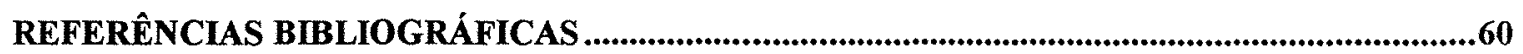


1. Estimativas de saldo líquido migratório rural-urbano: Brasil - 1950/95

2. População migrante e não-migrante de acordo com faixas de anos de estudos... 24

3. Porcentagem dos trabalhadores migrantes e não migrantes de acordo com faixas de rendimentos mensais em reais.

4. População Migrante de acordo com faixas de idade que frequenta ou não escola ou creche

5. População Migrante que frequenta escola ou creche de acordo com situação de ocupação

6. Descrição, médias e desvios padrões das variáveis utilizadas no modelo

7. Modelo próbite de determinação da migração interna brasileira para 0 ano de 1998

8. Modelo próbite de determinação da migração interna brasileira para o ano de 1998 apenas para mulheres.

9. Modelo próbite de determinação da migração interna brasileira para o ano de 1998 apenas para homens 
LISTA DE GRÁFICOS

Página

1. Percentual de homens e mulheres da população brasileira não natural do município de residência

2. Composição de cor e raça da população não-natural no município de residência

3. Percentual das pessoas migrantes e não-migrantes que sabem e não sabem ler e escrever segundo domicílio

4. Idade da população residente e não-residente do município de residência 25

5. População não natural do estado de residência atual entre faixas de anos, que em 26 de setembro de 1998, morava, sem interrupção, na Unidade de Federação que reside

6. Percentual dos migrantes não-naturais da Unidade de Federação de residência atual, que moram a até quatro anos neste estado, sem interrupção, conforme anos de permanência

7. Percentual dos migrantes não-naturais da Unidade de Federação de residência atual, que moram de cinco a nove anos neste estado, sem interrupção, conforme anos de permanência. 
O RECENTE PROCESSO MIGRATORIO INTERNO BRASILEIRO E SEUS

DETERMINANTES

Autora: Viviane Mendonça Pereira Orientadora: Prfa. Ana Lúcia Kassouf

\section{RESUMO}

Utilizando microdados fornecidos pela PNAD - Pesquisa Nacional por Amostra e Domicílios (IBGE), este estudo, por meio de uma análise gráfica e tabular, procurou primeiramente abordar as principais características, composição e estrutura do atual processo migratório brasileiro.

Definindo o migrante como o indivíduo não natural do município de residência, o movimento migratório interno brasileiro, atualmente, é considerado menos intenso comparativamente a décadas anteriores, pois a participação dos migrantes na população total declinou e, hoje, os migrantes representam $32,9 \%$ da população total brasileira.

Os migrantes para o ano de 1998 são, na maioria, mulheres, possuem cor amarela e branca, estão situados na área urbana, possuem estrutura etária mais envelhecida, concentrando-se na faixa etária de 30 a 45 anos, e, principalmente, possuem nível de instrução e escolaridade superior ao dos indivíduos naturais do município de residência. Este maior nivel de instrução por parte dos migrantes possivelmente contribui para que estes apresentem niveis de rendimentos maiores que os dos não-migrantes. 
Posteriormente, por meio de um modelo econométrico, o atual trabalho procurou observar o comportamento das migrações internas brasileiras atuais $e$ seus determinantes. Como resultado, tem-se que as mulheres brasileiras são mais propensas a migrar do que os homens e que tanto os homens quanto as mulheres de cor amarela possuem maior propensão à migração do que os homens e mulheres que possuem a cor branca. $\mathrm{O}$ coeficiente estimado da cor parda para os homens apresentou sinal positivo, indicando que os homens pardos migram mais que os brancos, diferentemente do coeficiente das mulheres que apresentou sinal negativo, indicando que as pardas possuem menor propensão à migração do que as brancas. Com relação à cor negra, tanto os homens negros quanto as mulheres negras possuem menor probabilidade de deixar seu local de origem do que os homens e mulheres que possuem cor branca.

Observando a variável educação, conclui-se que os homens com maior nível de escolaridade migram mais com relação aos níveis baixos de escolaridade. Entretanto, há uma tendência de queda na magnitude dos efeitos marginais à medida que a educação aumenta. As mulheres apresentam o mesmo resultado apenas até atingirem 11 anos de estudo. Ao completarem aproximadamente o segundo grau, o aumento da escolaridade interfere negativamente na decisão da mulher migrar, enquanto que o homem está sempre disposto e propenso à migração à medida que adquire maior instrução.

Observa-se também o aumento da idade aumenta a probabilidade dos indivíduos migrarem até um certo ponto, além do qual a probabilidade diminui. Com relação à influência do tamanho da família na propensão do indivíduo migrar, tem-se que os brasileiros migrantes em geral possuem menor probabilidade à migração à medida que possuem maior número de membros na família.

Para finalizar, conclui-se que os movimentos migratórios internos que anteriormente eram marcados pela condição de pobreza passaram a mesclar-se com fluxos migratórios de população de classe média e alta. Hoje em dia, à medida que 
aumenta sua renda per capita, o indivíduo possui maiores recursos para financiar sua migração e acresce sua probabilidade de deixar seu local de origem.

Assim, verifica-se com o atual trabalho que não são apenas as variáveis econômicas que influenciam a decisão migratória do indivíduo brasileiro. Constata-se que tanto variáveis econômicas quanto variáveis não-econômicas são significativas na determinação das influências da migração interna brasileira. 


\section{THE RECENT BRAZILIAN’S INTERNAL MIGRATORY PROCESS AND ITS}

\section{DETERMINANTS}

Author: Viviane Mendonça Pereira Adviser: Prfa. Ana Lúcia Kassouf

\section{SUMMARY}

This study, using micro-data supplied by PNAD - National Research of Home Samples (IBGE - Brazilian Institute of Geography and Statistics), and by means of graphic and tabulate analysis, approaches first the main characteristics, composition and structure of the current Brazilian migratory process.

Defining the migrant as the individual who is not a native of the municipality of residence, the domestic migratory movement in Brazil is, at present, considered less intense comparatively to previous decades, as the migrants participation in the total population declined and, nowadays, they represent $32.9 \%$ of the Brazilian total population.

According to the graphic and tabulate analysis, it is concluded that migrants in 1998 are mostly white and yellow skin women living in the urban area, with an older age structure, concentrating on the age group of 30 to 45 years. Especially, they possess a higher level of training and school education than the municipality native individual. The migrants' higher education level possibly contributes to their higher income levels when compared to those of non-migrant individuals. 
Later, this work tried watching the behaviour of the recent Brazilian domestic migrations and their determinants. As a result of the model, it is considered that Brazilian women are more likely to migrate than men, and that both yellow skin men and women have greater propensity to migrate than white coloured men and women. The estimated coefficient for brown coloured men showed a favourable sign, indicating that brown men migrate more than white men, different to the women's coefficient which showed a negative sign indicating that brown women show a smaller trend to migrate than white women. As to black skin people, both genders show lower probability of leaving their place of origin than whites.

Observing the variable education, it is concluded that men with higher school levels migrate more than those with lower school education, as all variable coefficients representing education were favourable. However, there is a decrease trend in the magnitude of marginal effects as education levels increase. Women show a similar result only until they get to their 11th year of school education. When they complete the second degree of school education, this will interfere negatively in their decision to migrate. Men, however, are always willing to migrate even with higher education.

It is also noticed that a more advanced age increases the individuals' probability to migrate, up to a certain point, beyond which the probability decreases. It is noticed that the family size influences the individuals' propensity to migrate and this applies to both genders. When families are formed by a larger number of members the migration probability decreases, due to greater difficulty in the adaptation of the whole family in the place of destination.

Finally, it is concluded that domestic migratory movements which, previously, were linked to poverty, now mix with middle and high class population migratory flows. This means that it is not just lower class individuals who leave their place of origin in search of a new life and opportunity. Nowadays, as the per capita income rises, the 
individual has more resources to finance his migration, and the probability of leaving the place of origin increases.

With this work, it may be seen that not just economic variables influence the Brazilian individual decision to migrate. It is noticed that economic variables as well as non-economic variables are significant in determining the influences in the Brazilian domestic migrations. 


\section{INTRODUÇÃO}

\subsection{Apresentação}

A mobilidade geográfica e espacial da população de um determinado país desempenha papel fundamental em muitas de suas estratégias de desenvolvimento. Assim sendo, o principal determinante de curto prazo das mudanças na distribuição da população, os movimentos migratórios internos ${ }^{1}$, possuem bastante relevância e expressão sócio-econômica. Além de envolver contingentes populacionais numerosos, estes movimentos migratórios acabam por refletir e condicionar algumas divergências regionais, dadas por maior ou menor interesse e atração por parte da população migrante.

As migrações internas de um país são um fenômeno que ocorre em todo o mundo, desenvolvido e subdesenvolvido, e as causas que os determinam têm muitas vezes variado no tempo. No passado, o movimento populacional se deu por motivos religiosos, industrialização, urbanização de grandes centros, entre outros. Presentemente, o movimento é uma forma basicamente de "sobrevivência", constituindo-se, na verdade, num deslocamento em busca de emprego e melhoria do bem estar da população.

Os deslocamentos migratórios ocorrem devido, principalmente, a decisões voluntariamente tomadas pelos indivíduos em resposta a fatores econômicos, sociais e 
culturais, que assumem formas diferenciadas nos locais de origem e de destino. Estes fatores que entram na decisão do indivíduo migrar são denominados fatores de atração e expulsão. Os fatores de expulsão definem as áreas de onde se originam os fluxos ou movimentos migratórios, mas são os fatores de atração que determinam a orientação destes fluxos e as áreas às quais se destinam.

Além de levar em consideração os fatores de expulsão e de atração, também pode-se ressaltar a importância dos obstáculos que se interpõem à migração, como distância, encargos sobre o migrante, entre outros, e os fatores pessoais que afetam a tomada de decisão.

Assim, o propósito do presente trabalho é desenvolver um estudo, utilizando dados recentes, a respeito dos movimentos migratórios internos brasileiros. Neste estudo, levando em consideração variáveis econômicas e não-econômicas, serão analisadas as causas e características das migrações internas e discutidas comparativamente a trabalhos realizados para outros países e para o Brasil.

\subsection{Justificativa}

Como já foi dito anteriormente, a mobilidade geográfica da população de um determinado país desempenha papel fundamental em muitas de suas estratégias de desenvolvimento econômico e social.

No Brasil, a heterogeneidade espacial da economia é bem conhecida e, sempre, juntamente com as mudanças espaciais da atividade econômica principal ganha relevância os movimentos migratórios internos. Muitos estudos e análises já foram

\footnotetext{
${ }^{1}$ De modo geral, define-se como movimento migratório, o movimento que leva a mudança permanente ou semipermanente de residência
} 
elaborados para o caso brasileiro, mas a maioria, nas áreas das regiões de São Paulo e Nordeste, principais focos de migrações internas; ou, então, discutem apenas influência de variáveis econômicas, como diferenciais de rendas entre estados ou regiões e custos da migração, sobre os fluxos migratórios.

Assim, espera-se que o presente trabalho possa trazer uma importante contribuição por analisar os movimentos migratórios internos do Brasil levando em consideração variáveis tanto econômicas quanto não-econômicas, utilizando os mais recentes dados disponíveis a respeito de migrações internas brasileiras e, também, por comparar este estudo com alguns já desenvolvidos em outros países e até mesmo no Brasil, em outros períodos.

\subsection{Objetivos}

O objetivo geral do presente trabalho é elaborar um estudo para o ano de 1998, discutindo as causas e características das migrações internas do Brasil, dando maior ênfase ao papel da educação no processo migratório brasileiro. Como objetivo específico, procura-se caracterizar o processo atual migratório no Brasil por meio de uma análise gráfica e tabular, usando microdados fornecidos pela PNAD- Pesquisa Nacional por Amostra de Domicílios (IBGE) de 1998. Esses gráficos e tabelas permitirão uma abordagem das principais características, composição e estrutura das migrações internas, no país, no ano de 1998.

Em seguida, utilizando um modelo de regressão, onde a variável dependente assume valor 1 se o indivíduo for migrante e valor 0 se o indivíduo for não-migrante e também, definidas variáveis explicativas, econômicas e não-econômicas, como educação do migrante e do não migrante, remuneração do trabalho, idade, sexo, entre outras, será observado o comportamento das migrações internas atuais e o que leva e influencia 
atualmente um indivíduo a deixar seu lugar de residência em busca de uma nova vida e oportunidade. Será dada maior importância à discussão dos efeitos do nível de instrução dos migrantes e não migrantes no processo migratório interno atual, já que a educação desempenha papel fundamental na formação do mercado de trabalho.

\subsection{Revisão de Literatura}

Os estudos e pesquisas a respeito das migrações internas surgiram no final do século XIX, onde Ravenstein (1885) formulou uma série de leis e regras a respeito do fenômeno e que, de certa maneira, parecem ainda plenamente aceitas e atuais. Sua busca de regularidades nesses deslocamentos foi baseada nas estatísticas oficiais da Inglaterra daquele momento e ampliada, posteriormente, com evidências de outros paises europeus.

Para Ravenstein (1885), as causas e efeitos dos movimentos migratórios não eram necessariamente decorrentes de racionalização econômica dos migrantes, registrando-se, segundo sua opinião, fatores de natureza sociológica. Nas análises elaboradas na época, o autor concluiu que nas migrações internas atuavam fatores repulsivos intimamente ligados à estrutura e propriedade da terra, ao sistema de comercialização dos produtos agrícolas e à dispersão da renda. Do outro lado, serviam como atração o interesse pelo aumento de níveis de educação, a busca de novos e melhores empregos e, finalmente, o "brilho das cidades".

As leis das migrações enunciadas por Ravenstein (1885) constituem ainda hipóteses amplamente aceitas para descrever e explicar alguns fenômenos migratórios. As sete leis podem ser resumidas da seguinte maneira:

1) os deslocamentos se dão em direção aos centros industriais e comerciais; 
2) a maior parte dos migrantes procedem de áreas próximas;

3) os naturais de cidades (ou vilas) migram relativamente menos do que os naturais das áreas rurais;

4) a melhoria dos meios de transporte e locomoção induz a um aumento das migrações;

5) cada corrente migratória principal produz uma corrente inversa compensatória;

6) observa-se predominância de fatores econômicos dentre as causas migratórias e

7) as mulheres migram mais do que os homens.

Em 1965, Everett Lee elaborou um documento destacando que pouco se fez no campo das migrações internas após Ravenstein (1885). Segundo Lee (1965), é um equívoco focalizar o fenômeno numa classificação estritamente dicotômica: migração versus sexo, migração versus atividade econômica etc, sendo necessário focalizar com maior objetividade as razões para emigrar e a assimilação nas áreas destino.

Para o autor, os fatores que entram na decisão de migrar e o processo migratório podem ser visualizados de quatro pontos de vista interdependentes:
a) fatores associados ao local de origem;
b) fatores associados ao local de destino;
c) obstáculos intervenientes;
d) fatores pessoais.

É, sem dúvida, a Lee (1965) que devemos os termos "fatores de atração" e "fatores de expulsão", tão comumente utilizados até hoje na literatura especializada e nos meios de comunicação em geral. Vale acentuar que, para esse autor, a distância (dita como um obstáculo interveniente), a exemplo do pensamento de Ravenstein (1885), é 
variável de importância destacada na determinação, caracterização e análise do fenômeno.

No elenco de fatores causais do volume das migrações internas, Lee (1965) destaca como interferências o grau de diversidade das áreas, a natureza dos obstáculos (institucionais, culturais, geográficos) e as flutuações da economia. Também, segundo o autor, as migrações têm caráter seletivo, ou seja, as migrações são seletivas em razão das pessoas responderem de forma diferente a uma série de fatores positivos e negativos prevalecentes nos locais de destino e de origem, terem capacidades diferentes para superar as séries de obstáculos e diferenciarem-se em termos de fatores pessoais. Seria impossível, para ele, que as migrações deixassem de ser positivas em certas correntes e negativas em outras, entendendo-se por migração positiva a seleção de migrantes de alta qualidade e, por migração negativa, o contrário.

Além dessas formulações "clássicas" nos estudos de migrações internas, concordando com as preocupações de Lee (1965), pode-se enumerar uma série de estudos, quantitativamente significantes, que tratam de focalizar a problemática da marginalidade populacional, em especial dos migrantes rurais, nas áreas urbanas da América Latina. Nessa perspectiva, alguns modelos econométricos foram desenvolvidos, destacando-se o modelo de Todaro (1969) a respeito das migrações rurais-urbanas. Neste trabalho, o autor formulou um modelo econômico de comportamento da migração rural-urbana, baseado nos diferenciais de salários. Neste caso, assume papel de relevo a determinação de um parâmetro que deve exprimir as expectativas do migrante quanto às oportunidades de obtenção de emprego no setor moderno. Assim, na análise, é considerado não propriamente o diferencial de renda real prevalecente mas, sim o diferencial "esperado" pelo indivíduo migrante entre as rendas dos setores rural e urbano.

Em um outro trabalho, também realizado por Todaro \& Harris (1970), é tratado o fenômeno a partir de um modelo bi-setorial de migração rural-urbana. A suposição 
fundamental do modelo é que os fluxos migratórios rurais-urbanos persistirão enquanto a renda urbana esperada estiver sendo superior à produtividade agrícola real.

Outro trabalho também bastante interessante no que se refere às migrações rurais urbanas, foi elaborado por Todaro em 1971, onde é analisada a relação existente entre a migração, diferenciais esperados de renda e emprego urbano na África. Além disso, Todaro (1971) também sugere algumas políticas de curto e longo prazos que poderiam ser adotadas, a fim de conter o fluxo maciço de migrantes rurais e aliviar o problema do desemprego urbano crescente na África. Neste trabalho, Todaro responsabiliza a combinação de dois fatores econômicos pela taxa elevada de migração rural-urbana: a expectativa do migrante de maximizar a sua renda, levado por um diferencial esperado de renda entre os setores e a possibilidade do migrante conseguir um emprego urbano mais seguro.

Nakosteen e Zimmer (1980) utilizando dados de uma amostra de 9.223 indivíduos empregados ${ }^{2}$ para os anos de 1971 e 1973, descrevem um modelo simples de migração e acham evidência empírica da influência de variáveis não-econômicas ao explicarem os movimentos migratórios internos. Para cada indivíduo, foram coletados dados como idade, raça, sexo, renda per capita, estado onde trabalha, se é trabalhador autônomo e a variável regional, taxa de crescimento de empregos. Os indivíduos migrantes foram definidos como aqueles que mudaram de estado onde trabalham de 1971 para 1973. Como resultado, verificou-se que a probabilidade de migrar decresce com a idade e para pessoas que são autônomas. Os homens são mais propensos à migração e à medida que aumenta a renda per capita do indivíduo, maior a probabilidade dele deixar seu local de residência. Não se pode observar os resultados da variável raça, pois o coeficiente estimado não apresentou-se estatisticamente diferente de zero.

\footnotetext{
${ }^{2}$ Dados obtidos pelo "Social Security Administration Continuous Work History Sample (CWHS).
} 
Outro trabalho que trata o fenômeno migratório dos Estados Unidos, foi realizado por Kaluzny (1975). Este estudo utilizou dados anuais dos anos de 1968-1969 e 1969-1970, para indivíduos com menos de 45 anos que se encontravam economicamente ativos. A variável dependente utilizada é a migração residencial que ocorreu durante o período observado. As variáveis independentes utilizadas foram o tamanho da família, se o migrante possui casa própria, se ocorreu criação de uma nova unidade residencial durante o período observado por um ou mais adultos da família, renda familiar, se ocomeu migração anterior do chefe da família para seu estado de origem, idade do chefe da família, nível de instrução do chefe da família e por último, rendimento deste após migrar.

Primeiramente, foram comparados os resultados do modelo para os indivíduos brancos e não-brancos. Como resposta, teve-se que tanto os brancos quanto os nãobrancos obtiveram significativa interação negativa com as variáveis idade e possuir casa própria. Assim, quanto maior a idade e se a família possui casa própria, menor a probabilidade dos indivíduos migrarem. $\mathrm{O}$ efeito positivo encontrado da renda familiar sobre a migração é interpretado pelos custos e riscos associados aos movimentos migratórios. Estes riscos, dados pela possibilidade de não conseguir emprego ou de obter uma menor renda no local de destino, serão minimizados à medida que a família possui um maior potencial econômico para a transição.

Posteriormente, foram comparados os resultados do modelo para indivíduos com diversos graus de poder aquisitivo. Como resultado, o coeficiente significativo para a variável raça, que foi incluida nesta análise, implica na existência de um efeito racial que é claramente distinto de acordo com as condições de pobreza. Para o autor os nãobrancos podem migrar menos pela alta incidência de baixa renda residencial.

A variável idade apresentou sinal negativo para todas as classes econômicas, indicando que quanto maior a idade do indivíduo, independentemente do seu poder aquisitivo, menor é a probabilidade de migrar. Já a variável expectativa de renda no 
local de origem apresentou sinal positivo para todos os grupos, sinalizando que quanto maior a expectativa de ganho, maior é a probabilidade de migração. O coeficiente estimado para a variável renda familiar foi significante para todas as classes sociais, exceto para o grupo de indivíduos que possui maior poder aquisitivo. Assim, para os pobres, quanto maior sua renda, maior a probabilidade de deixar seu local de origem e migrar.

Por último, o estudo que chamou maior atenção, por apresentar uma análise também pretendida pelo presente trabalho, foi elaborado em 1999, por Yaohui Zhao. Este trabalho analisa a migração rural urbana na China e acha evidência empírica que a decisão de migrar dos chineses rurais é afetada por forças não-econômicas.

Para Zhao (1999), o diferencial de renda entre os setores não é o único fator determinante da migração, pois além dele, são também determinantes o sexo, a idade, os diferenciais de qualidade de vida das áreas rurais e urbanas, custos da migração e escolaridade.

No trabalho realizado por Zhao (1999), os trabalhadores rurais foram classificados em três categorias: trabalhadores que moram e trabalham na área rural (trabalhadores rurais), trabalhadores que moram no campo, mas não trabalham na área rural (trabalhadores não rurais) e trabalhadores migrantes ( trabalhadores rurais que ingressaram no processo migratório pelo menos há três meses). Para o propósito das análises estatísticas, a amostra de trabalhadores foi construída por trabalhadores entre 15 e 65 anos e, além disso, foram excluídos os trabalhadores com o nível superior de estudo. Da amostra de 4.942 trabalhadores, 418 (8,5\%) eram migrantes, $452(9,1 \%)$ eram trabalhadores não rurais e $4.072(82,4 \%)$ eram trabalhadores rurais.

A variável dependente é uma escolha binária de migrar, assumindo valor 1 , versus permanecer em casa, assumindo valor 0 . As variáveis independentes representam características pessoais do trabalhador ou da comunidade, como idade, sexo, estado 
civil, nível de escolaridade, número de crianças por domicílio que freqüenta a préescola, possíveis posses de terras e situação de pavimentação das ruas. Os resultados do estudo mostraram que a maioria dos trabalhadores migrantes era mais jovem, do sexo masculino e não casada. A propensão a migrar do trabalhador diminuiu com a idade. $\mathrm{O}$ migrante da amostra apresentou, em média, 35,6 anos. Observou-se que cada ano adicional reduziu a probabilidade de migrar em $3,5 \%$. O efeito negativo é presente para todas as idades e passa a ser maior com o aumento desta.

O número de crianças na pré-escola, por família, não foi estatisticamente significante no estudo de Zhao. Já o contrário ocorreu com a relação migração e volume de terra per capita em uma família, pois como a terra é uma determinante da renda agrícola, reduções nos tamanhos das posses tendem a reduzir a renda e aumentar a motivação aos movimentos migratórios. A variável educação teve um surpreendente pequeno efeito sobre a migração. Comparados com trabalhadores sem estudo, os trabalhadores com estudo primário ou secundário não tendem a ter maior propensão ou motivação à migração. Assim, a educação não foi uma variável significativa, rejeitando a hipótese de que ela tem papel positivo e importante nos movimentos migratórios.

A estatística não significante encontrada para a variável grau de instrução pode ser explicada pelo fato das pessoas com maior nivel de educação não possuírem incentivos em deixar o meio rural. Por este motivo, Zhao considera duas perspectivas, uma olhando o que atrai o trabalhador rural educado, fazendo com que ele permaneça no campo e também comparando as diferenças de rendas dos indivíduos migrantes e aqueles que preferem não migrar e continuar no meio rural.

Existem duas opções de emprego para o trabalhador rural: trabalhar no campo ou não trabalhar no campo. Para examinar qual das duas opções atrai o trabalhador rural mais instruído, foi necessário desagregar a amostra nestes dois grupos e depois examinar qual escolha é feita pelo trabalhador rural: trabalhar no campo, não trabalhar 
no campo ou migrar, permanecendo as mesmas variáveis independentes relacionadas no estudo anterior.

A resposta foi um pouco diferente. Apesar da educação ainda não apresentar efeito significativo na escolha do trabalhador migrar ou não migrar, o efeito da escolarização se tornou forte e bastante significativo quando examinada a possível escolha entre o trabalho rural e o trabalho não rural. Comparando trabalhadores com e sem instrução, a probabilidade do primeiro escolher o trabalho não rural é $20 \%$ maior do que escolher o trabalho rural. Assim, na China, os indivíduos com maior grau de instrução tendem a preferir trabalhos não rurais a migração.

Assim, para finalizar, Zhao (1999) examina os diferenciais de renda dos trabalhadores rurais, não rurais e migrantes e conclui que a contribuição marginal dos trabalhadores migrantes é a maior, ou seja, um trabalhador que deixa o trabalho rural e migra contribui para um aumento de $49,1 \%$ da renda familiar. Já o trabalhador que deixa o trabalho rural para o não rural, contribui para um aumento de $13 \%$ da renda familiar. Sendo assim, os trabalhadores rurais são os que possuem menor contribuição marginal na renda familiar.

A escolaridade tem um efeito muito pequeno ao se analisar os diferenciais de renda entre os setores. Assim, Zhao (1999) conclui que o grande diferencial de renda encontrado entre o trabalho migratório e o do setor não rural existe para indivíduos com todos os níveis de escolaridade. Então, se a migração leva a maiores rendimentos, Zhao (1999) questiona o motivo pelo qual os trabalhadores instruídos continuam preferindo o trabalho no campo ao invés de migrar e conclui que este fenômeno, pouco comum, pode ser explicado pelos custos migratórios impostos aos migrantes chineses.

A preocupação de relatar profundamente este trabalho realizado na China é pelo interesse em comparar este estudo com o trabalho aqui pretendido, pois apesar de se tratar de migrações rurais-urbanas e de serem trabalhos realizados para diferentes países, 
- trabalho realizado por Zhao (1999) é bastante atual, analisa variáveis bastante importantes e influentes no processo migratório e dá bastante ênfase à influência da educação nos movimentos.

Apesar de reconhecida a importância do fenômeno das migrações internas no Brasil, grande parte dos trabalhos efetuados no país tem caráter essencialmente descritivo ou se limita a áreas bem definidas e específicas. As monografias elaboradas por Sahota (1968) e Graham (1973) incluem-se dentre as mais importantes na análise do fenômeno brasileiro.

O primeiro autor, Gian Sahota (1968), analisa o fenômeno através de técnica de regressão, testando, assim, as relações entre variáveis econômicas e sociais para explicar as migrações internas no país.

Com esse propósito e manuseio estatístico, o autor define variáveis explicativas, tais como: taxa de remuneração do trabalho, educação, urbanização, densidade territorial, distância, industrialização, taxa de crescimento da população e dispersão da renda. O trabalho foi efetuado em nível estadual e com dados de 1950. Os resultados obtidos foram extremamente interessantes e constituem um ensaio altamente importante desse tipo de estudo para o país. Dentre as conclusões e observações notadas por Sahota (1968), destacam-se:

1) há relação inversa entre o volume das migrações e a distância;

2) há relação direta entre a densidade territorial e o poder de atração do estado, embora na área de origem essa variável não exerça influência;

3) o nivel da renda per capita explica o fenômeno e parece exercer influência tanto nas áreas de atração como nas de repulsão;

4) a educação parece ser outra variável altamente explicativa do fenômeno. O autor chama a atenção para o fato de que, dado um mesmo aumento no nível educacional em duas áreas, uma de origem e outra de destino, a área de 
origem tem poder de fixação de 2 a 4 vezes maior do que a atração exercida pela de destino;

É interessante notar que o autor não encontra nenhuma relação entre o volume migratório e a industrialização, sugerindo que este processo pouco pode explicar as migrações, mas, por outro lado, não chega a conclusões claras quanto aos efeitos da dispersão da renda.

O estudo feito por Graham (1973) tem outro sentido. Trata-se de verificar os efeitos das migrações interestaduais no processo de convergência regional da renda, ou seja, analisa o fenômeno da migração interna em volume e incidência diferencial, pelos vários estados do Brasil, bem como o seu papel no crescimento regional entre as décadas de 40 e 60 .

Estudando os decênios 40/50 e 50/60, entre outras observações e com base em correlações posicionais entre renda estadual, expressas em percentagem sobre a renda nacional, e a migração percentual, o autor apresenta alguns resultados, como:

a) os resultados das correlações diferem nos dois decênios;

b) as diferenças de renda têm um papel importante no movimento migratório interno;

c) os estados com maiores fluxos imigratórios entre 50/60, apresentaram, de modo geral, menores variações na renda per capita no mesmo período.

Outro trabalho interessante realizado para o Brasil é de Araújo \& Ramos (1999) que estuda os fluxos migratórios entre os estados como resultante dos diferenciais de renda e de taxas de desemprego através de dados da Contagem de 1996 (IBGE). Para a elaboração do trabalho foi utilizada apenas uma variável explicativa - a esperança de renda - variável também abordada pelo estudo de Harris \& Todaro (1970). Segundo os autores os resultados da regressão e a leitura dos dados sugere que os fluxos migratórios 
parecem ser adequadamente explicados por um modelo "a la Harris \& Todaro". Além disso, concluem que as menores taxas de desemprego aberto estão situadas nas áreas mais pobres do país, que são as que apresentam os maiores índices de expulsão de mãode-obra. Ao contrário disso, as áreas que apresentam maior desenvolvimento relativo (como São Paulo e Distrito Federal, por exemplo) tendem a apresentar as maiores taxas de desemprego aberto. Assim, é proposto que a melhor política para reduzir a taxa de desemprego nas regiões mais desenvolvidas consistisse na redução das disparidades de renda entre os diferentes espaços geográficos.

No que se refere a algumas abordagens mais descritivas, o trabalho apresentado por Mata, Carvalho \& Silva (1973) baseado no Censo Demográfico de 1972, é bastante interessante quando compara os migrantes e não-migrantes segundo diferentes indicadores, como renda média, grau médio de escolaridade, qualificação profissional etc. Os conjuntos de migrantes apresentaram características genericamente superiores ou equivalentes às dos não-migrantes, indicando uma forte seletividade daqueles. $\mathrm{Ou}$ seja, os migrantes conseguem, nas regiões de destino, níveis de rendimento iguais ou superiores aos dos não-migrantes, formam contigentes populacionais mais velhos e possuem superioridade dos níveis de educação escolar.

Já o trabalho realizado por Andrade (1979) descreve e analisa a procedência dos fluxos migratórios para o Recife, até a década de 70. O autor aborda que as trocas migratórias, em 1960-70, entre o Nordeste e o resto do país, tendo fixado o conceito de migrantes como referente aos não-naturais do estado em que se achavam residindo há dez anos ou menos, assinalaram como principais emissores regionais de população, em ordem decrescente, a Bahia (31\%), Pernambuco (18,4\%), a Paraíba $(11,8 \%)$ e o Ceará $(11,3 \%)$. E como principais estados de destino os do Sudeste do Brasil, que absorveram cerca de $70 \%$ dos migrantes, desses tendo São Paulo incorporado perto de $40 \%$ e o Rio de Janeiro cerca de $35 \%$. 
Entre 1950 e 1970, os migrantes que saíram do Nordeste e se orientaram para os centros urbanos intra-regionais eram indivíduos bastante jovens e do sexo feminino. Além disso, a migração de familias ganhou maior dimensão relativamente aos deslocamentos de indivíduos isolados. No Recife, apurou-se que, entre os não naturais, os graus de instrução mais avançados ocorriam sempre nas famílias de mais altos níveis sócio-econômicos, e ainda que $88 \%$ dos migrantes participavam de famílias em que a pessoa de maior escolaridade não ultrapassara os níveis elementar ou médio.

Por último, o trabalho de Patarra, Baeninger, Bógus \& Jannuzzi (1997) verificou os efeitos dos anos 80, a chamada "década perdida", nos deslocamentos populacionais. Para isto, foram utilizados dados do PRAD (Pesquisa Regional por Amostra Domiciliar) que abrange 150 municípios e 12.320 domicílios do estado de São Paulo. Os resultados encontrados evidenciaram algumas mudanças expressivas do fenômeno migratório para a década estudada. Os movimentos migratórios do tipo rural-urbano, que já eram decrescentes nos anos 70 , foram pouco significativos frente aos intensos deslocamentos entre áreas urbanas, os movimentos interestaduais de longa distância diminuiram sua participação no contexto paulista, ganhando maior importância os movimentos inter e intra-regionais, a dinâmica econômico-regional propiciou a inserção de cidades de porte intermediário e de pequeno porte como importantes áreas de atração populacional e indicadores de vida transformaram-se em um dos elementos considerados essenciais na decisão de migrar.

Além disso, a própria regionalização, advinda do intenso processo de urbanização e de redistribuição espacial da população e de atividades econômicas, fez emergir novas modalidades de deslocamentos populacionais, particularmente entre cidades vizinhas, configurando os movimentos pendulares. $E$, finalmente, os movimentos migratórios marcados pela condição de pobreza passaram a mesclar-se com fluxos migratórios de população de renda média e alta, já também ganhando algum destaque os deslocamentos de populações envelhecidas, fruto de alterações observadas no perfil demográfico da população brasileira. 


\subsection{Estrutura do trabalho}

Este trabalho está organizado em cinco capítulos. No primeiro, são abordadas a apresentação geral do tema a ser discutido, a revisão de literatura, os objetivos gerais e especificos e justificativa do problema escolhido. O segundo capítulo discute e analisa as migrações internas brasileiras atuais, de uma forma tabular e gráfica, possibilitando o conhecimento da estrutura e características gerais do processo migratório brasileiro recente. O capítulo 3 descreve a metodologia empregada para realizar os propósitos da presente pesquisa. No capítulo 4 são apresentadas as discussões e interpretações dos resultados obtidos e também comparações destes com trabalhos já realizados para países

como China, Estados Unidos, África e Brasil. E, finalmente, o capítulo 5 aborda as conclusões do trabalho. 


\section{CONSIDERAÇÕES E ESTATÍSTICAS BÁSICAS SOBRE O PROCESSO MIGRATÓRIO BRASILEIRO}

Para iniciar a análise recente dos movimentos migratórios internos no Brasil, é proveitoso identificar, rapidamente, as principais variações migratórias ocorridas nas últimas décadas.

As migrações internas começaram a desempenhar um papel de destaque na recomposição espacial da população somente a partir da década de 1930. Esses movimentos de população vincularam-se às transformações econômicas, sociais e políticas da sociedade brasileira. Nesta década, ocorreu o avanço da industrialização brasileira que passou a provocar uma situação de atração da população aos centros industrializados. Após a dinâmica de acumulação cafeeira, assiste-se, no país, o deslocamento do eixo dinâmico da economia, mais propriamente a configuração de uma dinâmica de acumulação assentada na indústria.

Os efeitos migratórios de tais processos foram bastante diversificados. Além das grandes migrações para as cidades e dos movimentos inter-regionais, foram se constituindo os movimentos em direção às fronteiras agrícolas e intensificando-se as migrações sazonais. Segundo o trabalho realizado por Mata, Carvalho \& Silva (1973), os estados do Rio de Janeiro, São Paulo e os estados do Sul predominaram nos anos trinta como principais áreas de imigração, tendo os estados do Leste e da parte meridional do Nordeste apresentado emigração significativa. A concentração do desenvolvimento industrial na região Centro-Sul e a progressiva integração do mercado interno, no 
entanto, propiciaram não somente o crescimento das cidades industriais, mas também o crescimento das cidades em todo território nacional, independente do grau de desenvolvimento local.

Esta situação continuou, na década de quarenta, embora tenha passado a prevalecer ritmo crescente de emigração em todo o Nordeste e em boa parte dos Estados do Leste. Além dos estados de São Paulo e Rio de Janeiro continuarem a absorver número significativo de imigrantes, o estado do Paraná, refletindo a forte atração exercida pela cultura do café sobre as migrações rurais- rurais, começou a se destacar, nessa época, como zona de fronteira importante para os fluxos migratórios interregionais.

De acordo com a Tabela 1 apresentada por Abramovay \& Camarano (1999), que mostra a evolução histórica dos saldos líquidos migratórios ${ }^{3}$ rural-urbano, pode-se observar um crescimento absoluto do saldo populacional que deixou o campo, até os anos 80 . Durante a década de 50 o saldo líquido total migratório foi de -10.824 mil habitantes, passando para -14.423 mil habitantes durante a década de 70 , expressando um crescimento migratório de aproximadamente $30 \%$. O fluxo que deixou o setor rural na década de 80 também foi expressivo: um terço de todos os que viviam no campo em 1980 saiu durante o período, o que representou aproximadamente 13 milhões de pessoas. Entre 1990 e 1995 este movimento migratório superou os 5,5 milhões de habitantes. Isto significa que, se este valor persistiu durante toda a década, $28 \%$ da população rural que vivia no campo em 1990 mudaram sua residência no ano 2000.

Durante a década de 60 , ocorreu um pequeno declínio nas taxas de emigração nos estados do Nordeste e incrementos nos estados do Leste. Registrou-se também uma ligeira queda da migração para São Paulo, declínio um pouco maior da que se orientou para o Rio de Janeiro, e redução drástica dos fluxos para o Paraná. A região Centro 
Oeste, na década de 60 , apresentou o mais elevado crescimento anual de população nos municípios, sendo responsável pelo fato a construção da capital Brasília e a rápida evolução da região (Graham, 1973).

Tabela 1. Estimativas de saldo líquido migratório rural-urbano: Brasil - 1950/95

\begin{tabular}{cc}
\hline Período & $\begin{array}{c}\text { Saldo Líquido Total } \\
\text { (em mil hab.) }\end{array}$ \\
\hline \hline $1950 / 60$ & -10.824 \\
$1960 / 70$ & -11.464 \\
$1970 / 80$ & -14.413 \\
$1980 / 90$ & -12.135 \\
$1990 / 95^{a}$ & -5.654 \\
\hline FONTE: IBGE, dados transformados e citados por Abramovay \& Camarano (1999) \\
a Taxa descenalizada para permitir a comparação
\end{tabular}

Entre as décadas de 50 e 70, o declínio da economia canavieira do Nordeste e da cafeicultura em Minas Gerais e Espírito Santo foram responsáveis pela liberação de um contigente populacional relevante das áreas rurais que, por sua vez, se deslocaram para os centros urbanos em busca de novas oportunidades. Também acompanhando a evolução das atividades produtivas do país, a população foi deslocando-se do campo para as cidades; entre 1940 e 1970, por exemplo, a população rural cresceu à taxa média anual de $1,8 \%$, enquanto a urbana expandiu-se a $4,8 \%$.

Os anos 70 , no entanto, foram marcados pela falência das fronteiras agrícolas enquanto áreas de atração e fixação de população. Em contrapartida, as áreas metropolitanas, particularmente a de São Paulo, constituíram o destino predominante dos principais fluxos migratórios.

\footnotetext{
${ }^{3} \mathrm{O}$ saldo líquido migratório rural-urbano é a diferença entre a população rural esperada apenas em função do crescimento vegetativo (natalidade menos mortalidade) e a população realmente encontrada no momento do censo.
} 
Além disso, ocorre também nesta década a taxação dos produtos agrícolas e incentivos fiscais à indústria e serviços urbanos, ficando dificil o trabalhador rural se manter na atividade agrícola e no campo.

As mudanças na estrutura agrária e o desempenho econômico das cidades de cada região eram importantes determinantes do processo migratório, ao menos até a década de 70. Em grande parte, a expulsão do campo era conseqüência da concentração da estrutura fundiária. A incapacidade das economias urbanas de reter a população expulsa impulsionava a migração interestadual, quer para as fronteiras agrícolas, quer sobretudo em direção às áreas urbanas do Sudeste. Este processo atingiu seu clímax na década de 70, quando a modernização agrícola fez a migração rural-urbana alcançar a cifra de 15,6 milhões de pessoas (Patarra, Baeninger, Bógus \& Jannuzzi, 1997).

Ao lado dessas capitais industriais, de forma mais clara apenas depois de 1980, um conjunto de cidades médias do Sudeste do país também já emergiam como outros importantes locais de destino dos movimentos migratórios.

Alguns estudos mais recentes evidenciam transformações acentuadas nos volumes, fluxos e características dos movimentos migratórios no Brasil a partir dos anos 80 , quando comparados com resultados encontrados nas décadas anteriores. O menor crescimento das metrópoles, a maior predominância de migrações de curta distância e intra-regionais, uma incidência acentuada de migrações de retorno, sugerindo uma circularidade de movimentos, a tendência de crescimento de cidades de porte médio, a configuração generalizada de periferias no entorno dos centros urbanos maiores, entre outras características, suscitou a afirmação, por parte de alguns especialistas, de se tratar da configuração de um novo padrão migratório brasileiro (Patarra, Baeninger, Bógus \& Jannuzzi, 1997).

Já no que se refere aos dias atuais, conforme dados disponíveis na PNAD, os movimentos migratórios internos na atual década foram menos intensos que nas 
anteriores, fazendo com que a participação dos migrantes na população do país venha declinando, ainda que lentamente. De 1993 para 1998, o percentual de pessoas não naturais do município de residência diminuiu de $40,5 \%$ para $39,2 \%$.

Os movimentos rurais-urbanos teve um declínio bastante significante na participação do fenômeno migratório interno brasileiro nos últimos anos. Os empregos e oportunidades em atividades não-agricolas, em setores como prestação de serviços, comércio, construção civil e a área social, constituem o novo leque de trabalhos disponíveis nas áreas rurais. Quatro em cada dez trabalhadores adultos nas áreas rurais trabalham em atividades não-agrícolas, um crescimento de $35 \%$ em menos de dez anos. (PNAD 98).

No ano de 1998 , na região Norte, apenas $5,27 \%$ da população não nasceu no lugar de residência. Enquanto isso, na região Centro-Oeste, este valor aumenta para $9,58 \%$, na região Sul para $17,16 \%$, na região Nordeste para $22,25 \%$ e , finalmente, na Região Sudeste o valor é de $45,74 \%$ da população. ${ }^{4}$ Assim, a região Norte é a que apresenta menor participação de migrantes, ou pessoas não naturais do município de residência, em sua população, enquanto na região Sudeste, $45,74 \%$ da população é originária de outras regiões. Conclui-se, então, que a região Sudeste constitui ainda um grande polo de atração para moradores de outras regiões do país, enquanto que a região Norte, provavelmente, constitui um polo de expulsão para estes.

De acordo com a população rural e urbana, somente $19,39 \%$ da população rural não nasceu no local de residência; enquanto isso, $80,61 \%$ da população urbana mora em municípios diferentes daqueles que nasceu. Esta relação mostra que as migrações são mais freqüentes na área urbana. Apesar de ter ocorrido, em certos períodos, importantes

\footnotetext{
${ }^{4}$ A Região Norte é constituída pelos estados de Rondônia, Acre, Amazonas, Roraima, Pará, Amapá e Tocantins. A Região Nordeste é constituída pelos estados do Maranhão, Piauí, Ceará, Rio Grande do Norte, Paraíba, Pernambuco, Alagoas, Sergipe e Bahia. A Região Sudeste é constituída pelos estados de Minas Gerais, Espírito Santo, Rio de Janeiro e São Paulo. A Região Sul é constituída pelos estados de Santa Catarina e Rio Grande do Sul. E, finalmente, a Região Centro-Oeste é constituída pelos estados de Mato Grosso do Sul, Mato Grosso, Goiás e Distrito Federal.
} 
fluxos urbano-rurais ou rurais-rurais, o setor urbano é o grande acolhedor de migrantes brasileiros, ou seja, este setor é, sem dúvida, mais atraente às pessoas dispostas a deixar seu lugar de origem e migrar.

Apesar de ser uma diferença pequena, as mulheres são maioria na participação dos migrantes brasileiros, representando um percentual de $52,48 \%$ da população migrante total (Gráfico 1).

Gráfico 1. Percentual de homens e mulheres da população brasileira não natural do município de residência

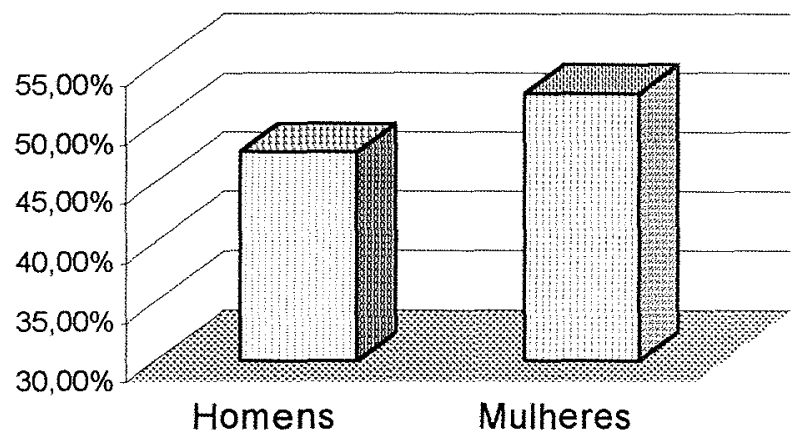

FONTE: PNAD 1998

A população migrante possui $40,91 \%$ do total da população da cor branca do país, $36,83 \%$ da população total da cor parda, $37,58 \%$ do total da população de cor negra, $46,84 \%$ da população total indígena e, finalmente, possui $59,32 \%$ do total da população amarela existente no país. Assim, pode-se dizer que os migrantes são em maioria brancos, pois esta população branca representa $54 \%$ da população total brasileira, e que a população amarela, no Brasil, possui maior propensão à migração (Gráfico 2). 

residência

Gráfico 2. Composição de cor e raça da população não-natural no município de

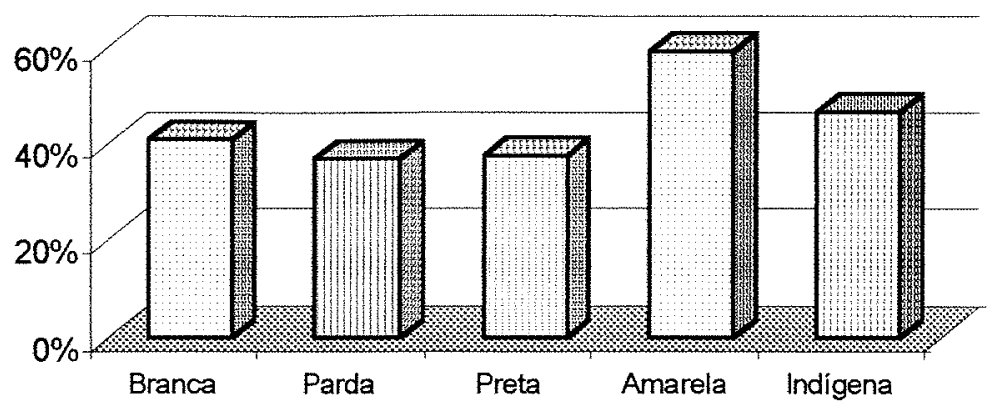

FONTE: PNAD 1998

Gráfico 3. Percentual das pessoas migrantes ${ }^{5}$ e não-migrantes que sabem e não sabem ler e escrever segundo domicílio

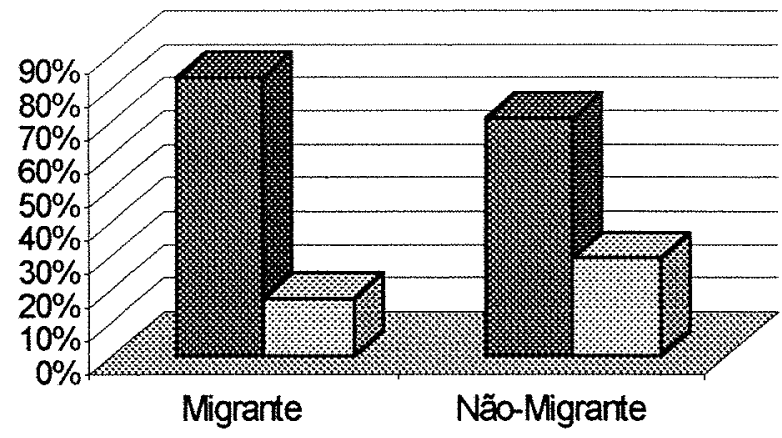

⿴囗大 sabem ler e escrever 중 não sabem ler e escrever

FONTE: PNAD 1998

Para analisar o grau de instrução das pessoas naturais e não-naturais do município de residência, o Gráfico 3 mostra que $83,08 \%$ dos migrantes, ou não-naturais, sabem ler e escrever, em contraste com 70,94\% dos não migrantes. Assim, verifica-se

${ }^{5}$ A população migrante é constituída pelos indivíduos não naturais do município de residência. 
um maior nível de escolaridade e instrução por parte das pessoas não originárias do local de residência.

Também para analisar a instrução dos migrantes e não-migrantes brasileiros, a Tabela 2 mostra os percentuais da população conforme faixas de anos de estudo e, chama a atenção o fato de que quase um terço $(32,75 \%)$ da população não-migrante possui menos de um ano de estudo, em contraste com aproximadamente $20 \%$ dos migrantes que possui tal instrução. Exceto para esta e para as faixas de 1 e 2 anos e 9 e 10 anos de estudo, a porcentagem de migrantes em todas as faixas de anos de estudo é maior do que para os não-migrantes. Aproximadamente $13 \%$ da população migrante terminou o primeiro grau, $11 \%$ terminou o segundo grau e $5 \%$ possui curso superior. Já a população não-migrante, $10 \%$ desta população terminou o primeiro grau, $9 \%$ o segundo grau e apenas $3 \%$ da população terminou um curso superior. Pode-se portanto, concluir que os migrantes são mais qualificados e, consequentemente, mais preparados para o mercado de trabalho do que os indivíduos não-migrantes.

Tabela 2. População migrante e não-migrante de acordo com faixas de anos de estudos

\begin{tabular}{lrrrr}
\hline $\begin{array}{l}\text { Anos de estudol } \\
\text { população }\end{array}$ & $\begin{array}{c}\text { População } \\
\text { Migrante }\end{array}$ & $\mathrm{Em}(\%)$ & $\begin{array}{c}\text { População } \\
\text { Não-Migrante }\end{array}$ & $\mathrm{Em}(\%)$ \\
\hline menos de 1 ano & 12110000 & $19,52 \%$ & 31490000 & $32,75 \%$ \\
\hline 1 e 2 anos & 6360254 & $10,25 \%$ & 11191528 & $11,64 \%$ \\
\hline 3 e 4 anos & 14294087 & $23,03 \%$ & 16559814 & $17,22 \%$ \\
\hline 5 e 6 anos & 7451259 & $12,01 \%$ & 10297099 & $10,70 \%$ \\
\hline e 8 anos & 7971340 & $12,85 \%$ & 9662921 & $10,05 \%$ \\
\hline e 10 anos & 2808463 & $4,52 \%$ & 4466536 & $4,65 \%$ \\
\hline 11 e 12 anos & 7075865 & $11,40 \%$ & 8349811 & $8,69 \%$ \\
\hline 13 e 14 anos & 867081 & $1,40 \%$ & 1135711 & $1,18 \%$ \\
\hline 15 ou mais anos & 2875632 & $4,63 \%$ & 2720768 & $2,83 \%$ \\
\hline $\begin{array}{l}\text { não determinado ou sem } \\
\text { declaração }\end{array}$ & 241196 & $0,39 \%$ & 284538 & $0,30 \%$ \\
\hline Total & 62055177 & $100 \%$ & 96158726 & $100 \%$ \\
\hline
\end{tabular}

FONTE: PNAD 1998 
Conforme o Gráfico 4, os migrantes apresentam estrutura etária mais envelhecida em decorrência de as levas migratórias apresentarem maior concentração de pessoas adultas que se deslocam em busca de melhores oportunidades de trabalho. Em 1998, a população migrante se concentra na faixa de 30 a 45 anos, enquanto que a população não-migrante apresenta maior concentração na faixa de idade inferior a 15 anos, alcançando nesta faixa de idade $41,66 \%$ do total da população não-migrante, enquanto que a população migrante alcançou apenas $11,98 \%$ do total de migrantes. Em conseqüência da estrutura etária mais envelhecida, os migrantes apresentam maior participação na força de trabalho que os não migrantes. A taxa de atividade das pessoas de 10 anos ou mais de idade foi de $57,9 \%$ para as naturais e de $62,9 \%$ para as nãonaturais do município. Para as pessoas não-naturais da Unidade da Federação de residência esta taxa alcançou 63,4\% (PNAD 1998). residência

Gráfico 4. Idade da população residente e não-residente no município de

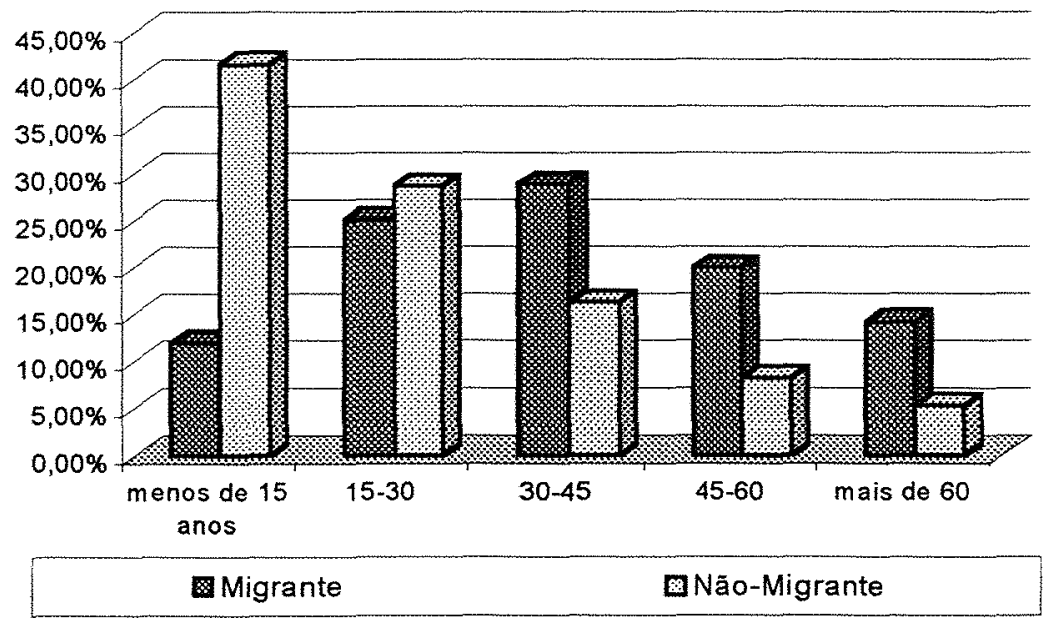

FONTE: PNAD 1998

Outro ponto bastante importante a ser observado é a comparação do rendimento mensal das pessoas naturais e não-naturais do município de residência. Conforme a 
Tabela 3, pode-se constatar que a população migrante possui maiores ganhos que a população não-migrante. A porcentagem de população não-migrante é superior à de migrante entre as faixas de rendimento de menos de $R \$ 100,00$ e de $R \$ 100,00$ a $\mathrm{R} \$ 300,00$, o contrário pode-se observar quando as faixas de rendimento são superiores a $\mathrm{R} \$ 300,00$. Do total da população que possui rendimento inferior a $\mathrm{R} \$ 100,00,59 \%$ são não-migrantes. Entretanto, do total da população que possui rendimento superior à $\mathrm{R} \$ 5.000,00$, aproximadamente, $60 \%$ são migrantes. Levando em consideração a renda per capita dos brasileiros, tem-se que os migrantes possuem em média renda per capita igual a $\mathrm{R} \$ 305,00$ e os não-migrantes $\mathrm{R} \$ 231,00$.

Tabela 3. Porcentagem dos trabalhadores migrantes e não migrantes de acordo com faixas de rendimentos mensais em reais.

\begin{tabular}{lrr}
\hline faixas de rendimento mensal/ população & Migrante & Não-Migrante \\
\hline menos de 100 & $41,00 \%$ & $59,00 \%$ \\
\hline de 100 à 300 & $47,70 \%$ & $52,30 \%$ \\
\hline de 300 à 500 & $54,79 \%$ & $45,21 \%$ \\
\hline de 500 à 700 & $56,65 \%$ & $43,35 \%$ \\
\hline de 700 à 900 & $56,53 \%$ & $43,47 \%$ \\
\hline de 900 à 1.500 & $56,12 \%$ & $43,88 \%$ \\
\hline de 1.500 à 5.000 & $57,30 \%$ & $42,70 \%$ \\
\hline mais que 5.000 & $59,84 \%$ & $40,16 \%$ \\
\hline FONTE: PNAD 1998 & &
\end{tabular}

Dos migrantes não naturais do município de residência, $40 \%$ não nascerão na Unidade da Federação em que moram. Assim, pode-se dizer que, em 1998, 40\% dos migrantes eram intra-regionais e $60 \%$ inter-regionais.

De 1993 para 1998, a porcentagem dos migrantes não naturais da Unidade da Federação de moradia caiu de $16,0 \%$ para $15,7 \%$ da população total brasileira, mostrando que a população migrante está, aos poucos e bastante lentamente, retornando ao seu lugar de origem. Em termos regionais, a estrutura da região Nordeste continuou 
mostrando os efeitos das saídas históricas de sua população em busca de condições de vida melhores em outras áreas do país, e a região Centro-Oeste, os reflexos das fortes correntes migratórias recebidas nas últimas décadas. Ainda que a Região Norte também tenha absorvido grandes contigentes de migrantes nos últimos decênios, a pesquisa não capta todos os efeitos desse afluxo de pessoas por não cobrir a sua área rural.

Em 1998, os migrantes inter-regionais são, majoritariamente, originários do Nordeste, pois $42,5 \%$ da população migrante não natural da Unidade de Federação em que reside nasceu na região Nordeste. Enquanto isso, 29,8\% da população nasceu nos estados da região Sudeste, $15,20 \%$ nos estados da região Sul, 5,5\% nos estados da região Centro-Oeste e, finalmente, $4 \%$ nasceu nos estados da região Norte.

Destes migrantes inter-regionais que nasceram em estados diferentes do qual residem, 65,5\% moram, sem interrupção, há 10 anos ou mais na Unidade da Federação de residência atual. Dos restantes, $15 \%$ moram no estado de residência atual de 5 a 9 anos e 19,5\% moram no máximo há 4 anos (Gráfico 5).

Gráfico 5. População não natural do estado de residência atual entre faixas de anos, que em 26 de setembro de 1998, morava, sem interrupção, na Unidade de Federação que reside

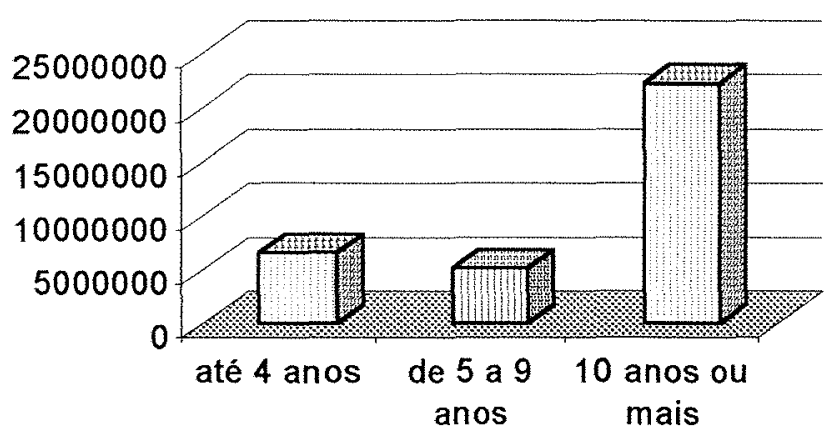


Destes últimos, $14,9 \%$ possuem residência fixa, sem interrupção há menos de 1 ano no estado, $22,6 \%$ há 1 ano, 22,3\% há 2 anos, $21,5 \%$ há 3 anos e 18,70\% há 4 anos (Gráfico 6). Já no que se refere aos migrantes que moram no estado de residência atual entre 5 e 9 anos, 24,7\% residem há 5 anos neste estado, sem interrupção, 21,20\% há 6 anos, $15,60 \%$ há 7 anos, $23,10 \%$ há 8 anos e, finalmente, 15,40\% dos migrantes moram neste estado há 9 anos (Gráfico 7).

Gráfico 6. Percentual dos migrantes não-naturais da Unidade de Federação de residência atual, que moram a até quatro anos neste estado, sem interrupção, conforme anos de permanência
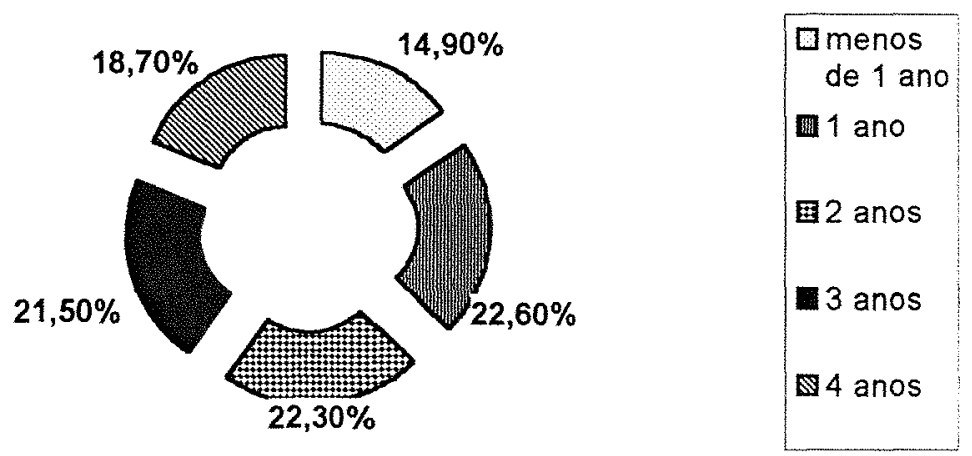

FONTE: PNAD 1998

Gráfico 7. Percentual dos migrantes não-naturais da Unidade de Federação de residência atual, que moram de cinco a nove anos neste estado, sem interrupção, conforme anos de permanência
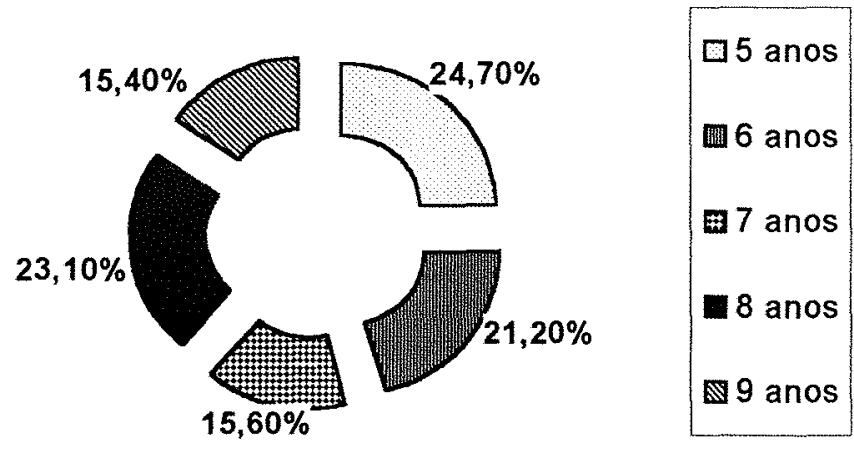

FONTE: PNAD 1998 
Ainda referente a estes migrantes que moram a menos de 4 anos no Estado de residência, aproximadamente $34 \%$ tiveram sua última residência fixada nos estados da região Nordeste, $32 \%$ nos estados da região Sudeste, $12 \%$ nos estados da região Sul e Centro-Oeste e $10 \%$ nos estados da região Norte.

Dos migrantes que moram há mais de cinco anos no estado de residência atual, aproximadamente $35 \%$ tiveram a última residência fixada nos estados da região Sudeste, $33 \%$ nos estados da região Nordeste, $15 \%$ nos estados da região Sul, $10 \%$ nos estados da região Centro-Oeste e, por último, $7 \%$ nos estados da região Norte.

Assim, pode-se observar que os estados que compõem a região Nordeste apresentaram ainda um fluxo significativo de migrantes para outros estados do país. A região Centro-Oeste, assim como a região Norte, aumentou seu percentual de migrantes que deixam a região. Já no que se refere as regiões Sul e Sudeste, este percentual de individuos que deixam a região em favor de outras, diminuiu.

Para concluir este capítulo, definindo o migrante como o individuo não-natural do município de residência, pode-se dizer que o movimento migratório interno, atualmente, é menos intenso comparado com décadas anteriores, pois a participação dos migrantes na população total declinou e, hoje, os migrantes representam $32,9 \%$ da população total brasileira.

Utilizando microdados fornecidos pela PNAD - Pesquisa Nacional por Amostras e Domicílios (IBGE), as tabelas e gráficos expostos neste capítulo nos mostram que os migrantes são, na maioria, mulheres, possuem cor branca, estão situados na área urbana, possuem estrutura etária mais envelhecida e, principalmente, possuem nível de instrução e escolaridade superior ao dos indivíduos naturais do município de residencia, o que possivelmente contribui para que estes migrantes apresentem níveis de rendimentos maiores que os dos não-migrantes. 
Além disso, ainda hoje possuindo maior número de migrantes em sua população, a região Sudeste é o grande polo de atração brasileiro, possuindo fatores que levam indivíduos de todo o país a migrarem em sua direção. Em contrapartida, as regiões Norte e Nordeste ainda permanecem sendo as regiões que mais perdem parcelas de sua população em função de outras regiões e são compostas por número pequeno de migrantes. 


\section{METODOLOGIA}

\subsection{Modelo}

Assim como o modelo utilizado por Yaohui Zahao (1999) no trabalho Labor Migration and Earnings Differences: The Case of Rural China, o presente trabalho irá utilizar um modelo de regressão não linear, bastante usado para tratamento de dados de censos estatísticos, onde a variável dependente assume valor 1 se o indivíduo analisado é migrante, ou valor 0 se o indivíduo é não-migrante, ou seja, esta variável dependente é conhecida como dicotômica ou binária.

Este modelo de escolhas binárias é caracterizado pelo fato de o indivíduo possuir duas alternativas, dentre as quais deve escolher uma. A escolha binária, representada pela variável aleatória $y_{i}$, assume os valores 1 ou 0 , assim que a escolha é feita. Se $P_{i}$ é a probabilidade de $y_{i}$ assumir valor 1 , então $1-P_{i}$ é a probabilidade de $y_{i}$ ser 0 . Assim, a função densidade de probabilidade de $y_{i}$ pode ser escrita:

$$
f\left(y_{i}\right)=P_{i}^{y_{i}}\left(1-P_{i}\right)^{1-y_{i}} \quad y_{i}=0,1
$$

A probabilidade de ocorrência de cada resposta, 1 ou 0 , de acordo com este modelo, é uma função de características sócio-econômicas individuais, tais como: idade, sexo, nível de instrução etc. 
Se forem definidas as utilidades derivadas pelas escolhas como a média da utilidade somado um erro aleatório, tem-se:

$$
\left\{\begin{array}{l}
U_{i 0}=\bar{U}_{i 0}+e_{i 0}=z_{i 0}^{\prime} \delta+w_{i}^{\prime} \gamma_{0}+e_{i 0} \\
U_{i 1}=\bar{U}_{i 1}+e_{i 1}=z_{i 1}^{\prime} \delta+w_{i}^{\prime} \gamma_{1}+e_{i 1}
\end{array}\right.
$$

onde $U_{i 0}$ e $U_{i l}$ são as utilidades das duas possíveis escolhas, $\bar{U}_{i 0}$ e $\overline{U_{i 1}}$ são as utilidades médias, $z^{\prime}{ }_{i 0}$ e $z_{i l}^{\prime}$ são vetores de características das alternativas, $w_{i}^{\prime}$ é um vetor das características sócio-econômicas dos indivíduos e $e_{i 0}$ e $e_{i 1}$ são distúrbios aleatórios.

As utilidades $U_{i 0}$ e $U_{i l}$ são aleatórias e o indivíduo só vai escolher a primeira alternativa se a utilidade adquirida pela sua escolha for maior que a utilidade adquirida pela escolha da segunda alternativa $\left(U_{i l}>U_{i 0}\right)$, ou se a variável aleatória não observada $y_{i}^{*}=U_{i l}-U_{i o}>0$. Consequentemente, os valores da variável aleatória observada são determinados por:

$$
y_{i}=\left\{\begin{array}{lll}
I & & y_{i}^{*}>0 \\
0 & \text { se } & y_{i}^{*} \leq 0
\end{array}\right.
$$

$$
\text { Susbtibuindo }\left\{\begin{array}{l}
U_{i 0}=\bar{U}_{i 0}+e_{i 0}=z_{i 0}^{\prime} \delta+w_{i}^{\prime} \gamma_{0}+e_{i 0} \\
U_{i 1}=\bar{U}_{i 1}+e_{i 1}=z_{i 1}^{\prime} \delta+w_{i}^{\prime} \gamma_{1}+e_{i 1}
\end{array} \quad \text { em } \quad y_{i}^{*}=U_{i 1}-U_{i 0}\right.
$$

pode-se reescrever $y_{i}{ }^{*}$ como:

$$
\begin{aligned}
& y_{i}^{*}=\left(z_{i 1}-z_{i 0}\right)^{\prime} \delta+w_{i}^{\prime}\left(\gamma_{1}-\gamma_{0}\right)+\left(e_{i 1}-e_{i 0}\right) \\
& =\left[\left(z_{i 1}-z_{i 0}\right)^{\prime}, w_{i}^{\prime}\right]\left[\begin{array}{c}
\delta \\
\gamma_{1}-\gamma_{0}
\end{array}\right]+e_{i}^{*} \\
& =x_{i}^{\prime} \beta+e_{i}^{*}
\end{aligned}
$$


onde $x_{i}{ }^{\prime}, \beta$ e $e_{i}{ }^{*}$ são variáveis explicativas, parâmetros e erros aleatórios, respectivamente. A probabilidade de $y_{i}=1$ é:

$$
P_{i}=P\left[y_{i}=1\right]=P\left[y_{i}^{*}>0\right]=P\left[e_{i}^{*}>-x_{i}^{\prime} \beta\right]
$$

É claro que para que o modelo fique completo, uma distribuição particular de probabilidade para $e_{i}{ }^{*}$ tem que ser escolhida. As duas mais comuns escolhas de distribuição são a normal padronizada e a logística. A distribuição de probabilidade da normal padronizada, é:

$$
F(t)=\int_{-\infty}^{t}(2 \pi)^{-\frac{1}{2}} \exp \left\{-\frac{x^{2}}{2}\right\} d x
$$

Dada uma amostra de $T$ observações independentes, onde as observações são distintas para cada indivíduo, a função de verossimilhança é dada por:

$$
\begin{aligned}
& L=\prod_{i=1}^{T} f\left(y_{i}\right)=\prod_{i=1}^{T} P_{i}^{y_{i}}\left(1-P_{i}\right)^{\left(1-y_{i}\right)} \\
& =\prod_{i=1}^{T} F\left(x_{i}^{\prime} \beta\right)^{y_{i}}\left[I-F\left(x_{i}^{\prime} \beta\right)\right]^{\left(1-y_{i}\right)}
\end{aligned}
$$

onde $F\left(\right.$.) é a distribuição de probabilidade normal padronizada e $y_{i}=l$ se a alternativa 1 for escolhida e $y_{i}=0$, caso contrário.

A função de verossimilhança ou sua forma logarítmica dada por:

$$
\ln L=\sum_{i=1}^{T} y_{i} \ln F\left(x_{i}^{\prime} \beta\right)+\sum_{i=1}^{T}\left(1-y_{i}\right) \ln \left[1-F\left(x_{i}^{\prime} \beta\right)\right],
$$

deve ser maximizada.

A sua derivada de primeira ordem é descrita abaixo: 


$$
\frac{\partial \ln L}{\partial \beta}=\sum_{i=1}^{T} y_{i} \frac{f}{F} x_{i}-\sum_{i=1}^{T}\left(1-y_{i}\right) \frac{f}{1-F} x_{i}
$$

onde $F$ é a função de distribuição de probabilidade e $f$ é a correspondente função de densidade.

A estimação dos parâmetros é então feita por métodos não lineares, já que a função acima não é uma função linear de $\beta$. Maiores detalhes podem ser observados em Judge et ali (1988).

Assim, o atual trabalho irá utilizar o modelo próbite, descrito acima, onde a variável dependente assumirá valor 1 se o indivíduo analisado é migrante, ou valor 0 se o indivíduo for não-migrante e as seguintes variáveis independentes: renda per capita, idade, anos de estudo, tamanho da familia, cor ou raça e sexo dos indivíduos.

O modelo econométrico será utilizado neste trabalho por apresentar vantagens sob as considerações gráficas e tabulares descritas no capitulo anterior. Por meio dele ocorrerá o controle das variáveis, pois serão incluídas todas na mesma regressão, ocorrerá a obtenção dos efeitos marginais das variáveis estudadas e assim será permitido a comparação com trabalhos já elaborados para outros países e também para o Brasil.

\subsection{Dados}

\subsubsection{A pesquisa}

Para a elaboração do presente trabalho serão utilizados microdados fornecidos pela PNAD/98 - Pesquisa por Amostra de Domicílios (IBGE). Trata-se de um sistema 
de pesquisas por amostra de domicílios que, por ter propósitos múltiplos, investiga diversas características sócio-econômicas, umas de caráter permanente nas pesquisas, como as características gerais da população, educação, trabalho, rendimento e habitação, e outras com periodicidade variável, como as características sobre migração, fecundidade, nupcialidade, saúde, nutrição e outros temas que são incluídos no sistema de acordo com as necessidades de informação para o país.

Os dados foram coletados em setembro de 1998 , onde aproximadamente 345.000 indivíduos foram entrevistados em 112.434 unidades domiciliares.

\subsubsection{Universo de análise}

Como visto anteriormente, a população migrante é composta em sua maioria por indivíduos com faixa etária mais envelhecida comparativamente aos não migrantes, estando concentrados na faixa etária entre 25-60 anos. Dentre os migrantes (Tabela 4), apenas $18,36 \%$ freqüentam escola ou creche, sendo que $16,17 \%$ correspondem às faixas etárias entre 0-25 anos e maiores de 60 anos. Além disso, 86,97\% desses indivíduos migrantes que freqüentam escola ou creche também trabalham (Tabela 5). Assim, é muito pequeno o número de indivíduos que escolhem a migração apenas para aperfeiçoarem seus estudos. Na maioria das vezes, a migração é marcada pela procura de um novo emprego. Levando estes fatos em consideração, para conduzir este estudo, restringiu-se o universo de análise a homens e mulheres na faixa etária entre 25-60 anos, ficando assim a amostra composta de 145.509 indivíduos. 
Tabela 4. População Migrante de acordo com faixas de idade que frequenta ou não escola ou creche

\begin{tabular}{l|r|r|r|r}
\hline $\begin{array}{l}\text { frequentam escola } \\
\text { ou crechelidade }\end{array}$ & até 25 & de 25 a 60 & mais de 60 & Total \\
\hline \hline sim & $16,12 \%$ & $2,19 \%$ & $0,05 \%$ & $18,36 \%$ \\
não & $14,37 \%$ & $54,74 \%$ & $12,53 \%$ & $81,64 \%$ \\
\hline FONTE: PNAD98
\end{tabular}

Tabela 5. População Migrante que frequenta escola ou creche de acordo com situação de ocupação

\begin{tabular}{l|r|r|r|r}
\hline ocupaçãolidade & até 25 & de 25 a 60 & mais de 60 & Total \\
\hline \hline ocupados & $61,55 \%$ & $25,15 \%$ & $0,27 \%$ & $86,97 \%$ \\
não ocupados & $11,58 \%$ & $1,44 \%$ & $0,01 \%$ & $13,03 \%$ \\
FONTE: PNAD98
\end{tabular}

A população amostrada é composta por 69.492 homens e 76.017 mulheres, a qual inclui indivíduos considerados migrantes e não migrantes. Da amostra selecionada 81.702 indivíduos são migrantes e 63.807 são não migrantes.

3.2.3 Descrição das variáveis

\subsubsection{Variáveis dependentes}

Migrante: a variável dependente utilizada no modelo não assume valores contínuos, ela representa resposta binária dos individuos, assumindo valor 1 se o indivíduo analisado é migrante e valor 0 se não migrante. É considerado migrante o individuo não natural do município de residência, ou seja, o indivíduo que não mora no local de origem ou nascimento. 


\subsubsection{Variáveis explanatórias}

Sexo: esta variável exógena também assume característica binária, representando o sexo feminino o valor 1 e o sexo masculino o valor 0 .

Acredita-se que o sexo relaciona a migração com as mulheres, ou seja, as mulheres seriam mais propensas a migrar do que os homens. Esta relação pode ser explicada pelas mulheres serem mais propensas a sair do campo ou do interior em busca de emprego e oportunidade em maiores centros urbanos, uma vez que, no seu local de origem, os trabalhos disponíveis são trabalhos agrícolas que exigem força, apropriados para homens.

Cor ou Raça: foram construídas variáveis binárias para os grupos de cor existentes no Brasil, que são as cores branca, amarela, parda e negra. Foi excluída a raça indigena por ser pouco representativa numericamente, e principalmente, por ter esta raça hábitos bastante distintos comparativamente ao resto da amostra.

Acredita-se existir uma relação positiva entre migração e indivíduos de cor amarela, pois foram os amarelos os últimos a ingressarem no Brasil como imigrantes, e possuem, até hoje, características aventureiras, dispostos a buscar novas oportunidades.

Educação: também foram construídas variáveis binárias para os grupos de anos de estudo dos indivíduos, agrupados em menos de 1 ano de estudo (EDU1), de 1 a 3 anos de estudo (EDU2), de 4 a 7 anos de estudo (EDU3), de 8 a 10 anos de estudo (EDU4), de 11 a 14 anos de estudo (EDU5), e finalmente, de 15 anos ou mais de estudo (EDU6). Dessa forma, as variáveis possibilitam que ocorram comparações quanto às pessoas sem instrução, com as que possuem aproximadamente o primário, ginásio, segundo grau, curso superior e pós graduação. Segundo o IBGE, apenas são considerados como sendo anos de estudo aqueles em que o indivíduo freqüentou escola e obteve aprovação em todas as disciplinas cursadas. 
O nível de instrução dos trabalhadores é um fator bastante relevante, já que este afeta diretamente a força de trabalho e a qualidade da mão-de-obra migrante. Acredita-se ocorrer uma relação positiva entre educação e os movimentos migratórios, uma vez que um maior nível de instrução do trabalhador poderia reduzir alguns custos psicológicos da migração e, principalmente, auxiliar na busca e disputa por melhores empregos.

Idade: como visto anteriormente, foram considerados na amostra apenas os indivíduos entre a faixa etária de 25-60 anos.

A idade é uma variável usualmente relatada como negativamente relacionada com a migração, porque as pessoas mais velhas seriam mais sensíveis às migrações e tornariam mais intensos os custos psicológicos e barreiras ao início de uma nova vida e trabalho.

Idade2: esta variável foi construída através da variável Idade:

Idade2=Idade $\times$ Idade

Com o auxilio da variável Idade2 pode-se observar a existência ou não de efeitos não lineares, especificamente, de parábola com vértice para cima, indicando crescimento ou decréscimo da probabilidade de se migrar à medida que ocorre o aumento da idade do indivíduo estudado.

Tamanho da família: esta variável assume valores contínuos e representa o número de componentes da família, incluindo agregados. Esta variável foi incluída para verificar se o número de pessoas na família afeta a decisão migratória do indivíduo. Acredita-se que quanto maior o número de componentes da família, menor a propensão do indivíduo deixar seu lugar de origem. 
Renda per capita: a variável renda per capita é contínua e foi construída a partir do valor do rendimento mensal familiar, inclusive agregados, correspondente a todos os trabalhos exercidos pelos indivíduos e do número de componentes da família.

Rendcap $=$ =rendimento mensal familiar/número de componentes da família, onde o índice $i$ refere-se a cada indivíduo.

Como fator de grande importância e influência sobre as migrações internas, a renda, na maioria dos trabalhos realizados, assume relação positiva com os movimentos migratórios, pois a migração ocorre à medida que o lugar de destino oferece maior rendimento e poder econômico ao indivíduo.

A média, desvios padrões e a descrição das variáveis utilizadas podem ser observadas na Tabela 6 , a seguir. 
Tabela 6. Descrição, médias e desvios padrões das variáveis utilizadas no modelo

\begin{tabular}{llrr}
\hline Variáveis & \multicolumn{1}{c}{ Descrição das variáveis } & Média & Desvio padrão \\
\hline \hline Migrante & 1 se o individuo é migrante & 0,561 & 0,496 \\
Sexo & 1 se o individuo é mulher & 0,522 & 0,499 \\
Branca & 1 se o individuo é branco & 0,534 & 0,498 \\
Amarela & 1 se o individuo é amarelo & 0,004 & 0,067 \\
Parda & 1 se o individuo é pardo & 0,395 & 0,488 \\
Negra & 1 se o individuo é negro & 0,063 & 0,243 \\
Edu1 & 1 se o indivíduo possui menos de 1 ano de estudo & 0,137 & 0,344 \\
Edu2 & 1 se o indivíduo possui de 1 a 3 anos de estudo & 0,155 & 0,362 \\
Edu3 & 1 se o indivíduo possui de 4 a 7 anos de estudo & 0,307 & 0,461 \\
Edu4 & 1 se o individuo possui de 8 a 10 anos de estudo & 0,137 & 0,344 \\
Edu5 & 1 se o individuo possui de 11 a 14 anos de estudo & 0,184 & 0,388 \\
Edu6 & 1 se o individuo possui 15 anos ou mais de estudo & 0,074 & 0,262 \\
Idade & anos de idade do individuo & 39,431 & 9,722 \\
Idade2 & idade ao quadrado & 1649,126 & 806.365 \\
Rendcap & Renda per capita mensal do indivíduo & 316,126 & 580,779 \\
Tamanho & número de componentes da família & \\
\hline
\end{tabular}

\footnotetext{
${ }^{6}$ Inclusive agregados.
} 


\section{RESULTADOS DO MODELO ECONOMÉTRICO}

Os determinantes dos movimentos migratórios internos no Brasil

Algumas variáveis que representam características pessoais e familiares, utilizadas para explicar as causas das migrações internas no Brasil são binárias, como o SEXO, os grupos de cores BRANCA - variável omitida, PARDA, AMARELA e NEGRA e os grupos de escolaridade que são: menos de 1 ano de estudo (EDU1) variável omitida, de 1 a 3 anos de estudo (EDU2), de 4 a 7 anos de estudo (EDU3), de 8 a 10 anos de estudo (EDU4), de 11 a 14 anos de estudo (EDU5) e 15 anos ou mais de estudo (EDU6). Além dessas variáveis, também são incluídas variáveis contínuas, como IDADE, IDADE2, o rendimento per capita mensal do indivíduo (RENDCAP) e o número de componentes da família (TAMANHO).

Os resultados econométricos do modelo próbite, estimado por máxima verossimilhança e ponderado pelo fator de expansão da amostra, estão representados na Tabela 6, onde a variável dependente Migrante é uma escolha binária da migração, assumindo valor 1 se o indivíduo não reside no local de origem e valor 0 se o indivíduo ainda permanece no município onde nasceu. Na Tabela 7 estão representados os efeitos marginais e os testes- $t$. 
Tabela 7. Modelo próbite de determinação da migração interna brasileira para o ano de 1998

\begin{tabular}{lc}
\hline Variáveis & MIGRANTE \\
\hline CONSTANTE & $-\mathbf{0 , 4 4 1 0 9}$ \\
\hline SEXO & $(-18,44)^{* * *}$ \\
\hline AMARELA & $\mathbf{0 . 0 1 2 1 5}$ \\
& $(4,62)^{* * *}$ \\
\hline PARDA & $\mathbf{0 , 1 5 8 8 0}$ \\
& $(9,03)^{* * *}$ \\
\hline NEGRA & $\mathbf{- 0 , 0 0 0 4 1}$ \\
& $(-0,14)$ \\
\hline EDU2 & $\mathbf{- 0 , 0 5 5 6 9}$ \\
\hline EDU3 & $(-9,90)^{* * *}$ \\
\hline EDU4 & $\mathbf{0 , 0 3 1 8 4}$ \\
& $(\mathbf{6 , 6 5 4})^{* * *}$ \\
\hline EDU5 & $\mathbf{0 , 0 5 8 0 1}$ \\
& $\left(\mathbf{1 3 , 4 4 ) ^ { * * * }}\right.$ \\
\hline EDU6 & $\mathbf{0 , 0 4 5 9 9}$ \\
& $\left(\mathbf{8 , 8 9 ) ^ { * * * }}\right.$ \\
\hline IDADE & $-\mathbf{0 , 0 1 3 2 5}$ \\
& $(-2,65)^{* * *}$ \\
\hline IDADE2 & $\mathbf{- 0 , 0 3 8 5 6}$ \\
\hline TAMANHO & $(-5,78)^{* * *}$ \\
\hline RENDCAP & $\mathbf{0 , 0 1 8 9 7}$ \\
\hline verossimilhança & $(15,81)^{* * *}$ \\
\hline
\end{tabular}

As estatísticas $-t$ são dadas entre parênteses abaixo dos efeitos marginais

* Significativo ao nivel de $10 \%$

**Significativo ao nível de $5 \%$

***Significativo Ao nivel de $1 \%$ 
Baseado no teste da razão de verossimilhança, o modelo é altamente relevante, rejeitando a hipótese nula do modelo não possuir poder explicativo para os movimentos migratórios internos brasileiros.

Todas as variáveis relacionadas no modelo foram estatisticamente significantes ao nível de $1 \%$, na determinação da migração interna, excluindo apenas a variável PARDA que compõe o grupo de cor ou raça, não significante.

A variável sexo apresentou sinal esperado, relacionando positivamente a migração com as mulheres. De acordo com o trabalho realizado por Andrade (1979), que estudou os fluxos migratórios nas décadas de 50-70 para o Recife, as mulheres, desde o início dos movimentos migratórios internos no Brasil, apresentam maior propensão a migrar do que os homens. Segundo os resultados obtidos no atual trabalho, a probabilidade de uma mulher migrar é 1,21 por cento maior do que um homem. Este resultado pode ser explicado pelas mulheres possuírem maior escolaridade comparativamente aos homens e, assim, possuírem maiores chances de serem empregadas no local de destino.

Resultado semelhante foi encontrado por Raveinstein (1885). Já Zhao (1999) que pesquisou as causas da migração na China, observou que os homens possuem uma maior propensão à migração. Este resultado foi explicado por problemas na política migratória chinesa, que possui barreiras para as migrações rurais-urbanas e pelos homens chineses possuírem maior escolaridade comparativamente às mulheres.

Semelhante à Zhao (1999), Nakosteen e Zimmer (1980), ao analisar as migrações internas norte-americanas, também encontraram sinal negativo para o coeficiente estimado da variável sexo. Observou-se que os homens possuem 8,2 pontos percentuais maior probabilidade à migração comparativamente às mulheres. 
As variáveis binárias para os grupos de cor existentes no Brasil (PARDA, NEGRA e AMARELA) foram incluídas no modelo para refletir diferenças étnicas e valores culturais entre os indivíduos. O grupo de referência é o da cor BRANCA (variável omitida do modelo). Observa-se sinal positivo para o coeficiente da variável cor amarela, tendo os indivíduos amarelos 15,88 por cento maior probabilidade a migrar do que os brancos. Já o coeficiente estimado para a variável cor negra apresentou sinal negativo e o resultado mostra que os indivíduos negros possuem 5,56 por cento menor probabilidade de migrar que os brancos. Por último, tem-se, como visto anteriormente, que o coeficiente da variável cor parda não foi estatisticamente significativo.

As variáveis binárias para os grupos de escolaridade (EDU2, EDU3, EDU4, EDU5 e EDU6), foram incluídas no modelo para verificar como o grau de educação interfere nos movimentos migratórios internos. O grupo de referência é o EDU1 (variável omitida do modelo), que representa os indivíduos com menos de 1 ano de estudo. Analisando os resultados observa-se que os coeficientes estimados para as variáveis EDU2, EDU3 e EDU4 apresentaram sinais positivos, indicando que individuos que adquirem maiores níveis de escolaridade possuem maior probabilidade à migração. O oposto é observado para a variável EDU5 e EDU6, que apresentaram sinais negativos, ou seja, quando um indivíduo alcança cerca de 11 anos de estudo, ou o segundo grau completo, o aumento da escolaridade não interfere positivamente na decisão do indivíduo migrar.

Pode-se dizer que os individuos que possuem de 1 a 3 anos de estudo, de 4 a 7 anos de estudo e de 8 a 10 anos de estudo apresentam, respectivamente, 3,18, 5,50 e 4,5 por cento maior probabilidade de migrar do que os indivíduos com menos de um ano de estudo. Este resultado indica que quanto maior o nível de instrução do indivíduo, menor serão os custos psicológicos ou barreiras encontradas por estes na obtenção de empregos ou na adaptação de uma nova vida no local de destino escolhido. 
Sahota (1968), Mata, Carvalho \& Silva (1973) e Andrade (1979) verificaram resultados semelhantes. Segundo Sahota (1979), a educação é uma variável altamente explicativa do fenômeno migratório interno brasileiro. $\mathrm{O}$ autor chama a atenção para o fato de que, dado um mesmo aumento no nível educacional em duas áreas, uma de origem e outra de destino, a área de origem tem poder de fixação de 2 a 4 vezes maior do que a atração exercida pela de destino. Também de acordo com Mata, Carvalho \& Silva (1973), o conjunto de indivíduos migrantes brasileiros apresenta escolaridade superior aos não migrantes. Resultado contrário a este foi verificado por Zhao (1999) que encontrou efeito negativo da educação sobre a migração. Na China, devido aos altos custos migratórios impostos aos migrantes, os trabalhadores instruídos preferem continuar trabalhando no campo ao invés de migrar.

Conforme dados do Banco Mundial (1990), no Kenya a probabilidade de uma pessoa educada deixar seu lugar de origem em busca de nova fixação residencial é cinco vezes maior comparativamente a indivíduos com baixo nível de escolaridade. Também na Tanzânia noventa por cento dos indivíduos que migram possuem algum tipo de instrução.

Székely, Duryea e Behrman (1999), ao realizarem um estudo para países da América Latina e para o Caribe relatam que as causas da migração podem mudar drasticamente de acordo com as condições vividas por um determinado país em um período de tempo. Um exemplo é dado para países que passaram por guerras ou alguma crise econômica, onde as primeiras pessoas que decidem migrar são aquelas com maior nível de escolaridade; já em outros momentos ocorre a predominância de migração daqueles com menor grau de instrução. Assim, semelhante ao resultado encontrado por Zhao, os autores sugerem que as migrações, de um modo geral, são mais intensas entre aqueles sem instrução.

A variável Idade é importante no modelo por analisar a estrutura etária da migração interna brasileira. Ao contrário do esperado, o sinal positivo do coeficiente 
estimado indica que os mais jovens têm menor probabilidade à migração. De acordo com o resultado encontrado, o aumento de 1 ano de vida do indivíduo acresce em 1,89 pontos percentuais a probabilidade deste indivíduo participar do movimento migratório interno. $\mathrm{Na}$ amostra utilizada pelo modelo, os migrantes apresentaram em média, 40 anos.

O sinal negativo encontrado para variável Idade2 indica que a migração com relação a idade segue uma forma parabólica, com vértice para cima, indicando que a partir de uma certa idade, no caso 59 anos, o indivíduo tem menor probabilidade de migrar comparativamente à probabilidade que teve com uma idade menor.

Resultado semelhante foi observado por Patarra, Baeninger, Bógus \& Jannuzzi (1997) que estudou os efeitos dos anos 80 nos deslocamentos populacionais internos brasileiros. Estes autores observaram um destaque no deslocamento das populações mais envelhecidas a partir dos anos 80 , em conseqüência de alterações observadas no perfil demográfico da população brasileira. Mata, Carvalho \& Silva (1973) que trabalharam com dados do Censo Demográfico de 1972, também observaram em seu estudo a predominância de um contigente migratório envelhecido.

O contrário foi encontrado por Zhao (1999), por Nakosteen e Zimmer (1980) e Kaluzny (1975). Zhao (1999) encontrou sinal negativo e altamente significativo para a variável idade, indicando que a propensão a migrar diminui na China com a idade. $O$ migrante da amostra utilizada pelo autor apresentou, em média, 35,6 anos e, como resultado encontrado, a cada ano adicional ocorre uma redução de 3,5 pontos percentuais da probabilidade de migrar. Também Nakosteen e Zimmer (1980) encontraram sinal negativo para o coeficiente estimado da variável idade ao estudar as causas da migração americana. Neste estudo conclui-se que a probabilidade de migrar decresce 0,8 pontos percentuais a cada ano adicional do indivíduo. 
A variável que representa o número de componentes da família, Tamanho, foi incluída no modelo para indicar se o número de pessoas que compõem a família é influência significativa na decisão de migrar. $O$ coeficiente negativo e altamente significativo encontrado para a variável, indica que, quanto maior o número de pessoas que compõem a família, menor a probabilidade do indivíduo decidir deixar seu local de origem. Conforme o resultado, um acréscimo de 10 componentes na sua família decresce em 8,61 pontos percentuais a probabilidade do indivíduo migrar. Assim, podese concluir que a variável Tamanho afeta a migração e este resultado pode ser explicado pela maior dificuldade encontrada na adaptação de todos os familiares no local de destino escolhido.

Resultado contrário foi encontrado por Andrade (1979) que estudou as trocas migratórias até a década de 70 entre o Nordeste e o resto do país. Neste estudo o autor aborda que a migração de famílias ganhou maior dimensão neste período, relativamente aos deslocamentos de indivíduos isolados anteriormente observados.

O coeficiente estimado para a variável Rendcap, que indica a renda per capita mensal, apresentou sinal positivo, indicando que os movimentos migratórios que anteriormente eram marcados pela condição de pobreza passaram a mesclar-se com fluxos migratórios de população de renda média e alta. Ou seja, observa-se que não são apenas os indivíduos de classe baixa que deixam seu local de origem em busca de nova vida e oportunidade. Conforme os resultados encontrados, um aumento de $\mathrm{R} \$ 1.000 \mathrm{em}$ sua renda acresce a probabilidade em 2,50 pontos percentuais do indivíduo deixar seu local de origem e migrar.

Este resultado pode ser explicado pelo indivíduo não estar satisfeito no local onde reside e acreditar que a decisão de migrar lhe traga alguma melhoria sócioeconômica. Assim, o sinal positivo para o coeficiente da variável Rendcap pode indicar que, à medida que aumenta seu rendimento, o indivíduo passa a obter maior recurso para financiar sua migração. 
A variável Rendcap é bastante importante na determinação dos fluxos migratórios internos e também bastante complexa e de dificil análise. Como os dados de renda per capita disponíveis para o presente estudo eram dados dos indivíduos que já haviam migrado ou ainda permaneciam no local de origem, pode-se analisar que uma maior renda é fruto da migração do indivíduo, ou ainda, que este indivíduo migrou por possuir maior renda. Assim, como visto em alguns trabalhos, seriam necessários os dados de renda per capita de alguns anos anteriores ou no momento da migração do indivíduo, os quais não estão disponíveis na PNAD. Portanto, a interpretação deve ser feita com cuidado.

Para minimizar os problemas existentes de análise, foi desenvolvido um modelo semelhante ao anterior onde os migrantes são indivíduos de 25 a 60 anos, que migraram interestadualmente e que moram na Unidade Federação de atual residência há 1 ano, ou menos, sem interrupção. Este modelo foi elaborado com o propósito de se observar o comportamento da variável Rendcap sem maiores limitações temporais, pois o migrante que mudou de residência há um ano ou menos ainda não teria tido tempo suficiente para alterar significantemente sua renda. $\mathrm{O}$ sinal positivo encontrado para a variável Rendcap neste modelo confirma o resultado anterior, isto é, que um maior rendimento possibilita e aumenta a probabilidade do indivíduo brasileiro migrar.

Ao analisar a mesma variável utilizada neste trabalho, renda per capita, Nakosteen e Zimmer (1980) também observaram sinal positivo e altamente significativo para o coeficiente estimado. Como resultado, observou-se que um aumento de $\mathrm{R} \$ 10,00$ em sua renda acresce a probabilidade em 14,55 pontos percentuais do indivíduo migrar.

Também Kaluzny (1975) encontrou efeito positivo para a variável renda familiar sobre a migração. Para o autor, este resultado é interpretado pelos custos e riscos associados aos movimentos migratórios. Estes riscos, dados pela possibilidade de não conseguir emprego ou de obter uma menor renda no local de destino, serão minimizados à medida que a família possui um maior potencial econômico para a transição. 
De acordo com dados do Banco Mundial (1990), na Índia, 78\% dos migrantes conseguem trabalho depois de um mês de nova residência e $94 \%$ depois de dois meses. Além disso, um estudo feito em Calcutá concluiu que, após o movimento migratório, o indivíduo encontra-se em melhores condições sócio-econômicas. Na Colômbia, assim como no Brasil, os migrantes possuem melhores rendimentos comparativamente àqueles que não deixaram seu local de origem.

Muitos trabalhos foram realizados com o propósito de explicar como o diferencial de renda entre os locais de origem e destino afetam o fenômeno migratório. Tal preocupação expressa que o indivíduo ao migrar espera obter maiores rendimentos e condições de vida. Assim, o acréscimo do seu rendimento faz com que aumente o potencial deste individuo migrar.

Todaro (1969), Todaro e Harris (1970) e Todaro (1971) analisam a relação existente entre a migração, diferenciais esperados de renda e emprego urbano. Nos trabalhos, conclui-se que combinação de dois fatores econômicos determinariam taxa elevada de migração rural-urbana: a expectativa do migrante de maximizar a sua renda, levado por um diferencial esperado de renda entre os setores e a possibilidade do migrante conseguir um emprego urbano mais seguro.

Para Sahota (1968) e Graham (1973) o nível de renda per capita e o diferencial de renda explicam o fenômeno migratório e parece exercer influência tanto nas áreas de atração como nas de repulsão. Graham (1973) explica que os estados com maiores fluxos migratórios entre 50-60 apresentaram, de modo geral, menores variações na renda per capita no mesmo período.

Patarra, Baeninger, Bógus \& Jannuzzi (1997) concluíram que os fluxos migratórios, a partir dos anos 80 , vêm ganhando bastante participação das classes mais favorecidas da população, ou seja, dos indivíduos que possuem maiores rendimentos. À 
medida que o indivíduo possui maior renda, também adquire maior potencial para deixar seu local de residência.

Ao aplicar o teste razão de verossimilhança com 13 graus de liberdade, que apresentou valor igual a 125,36 , rejeita-se a hipótese de que todos os coeficientes são iguais para homens e mulheres e verifica-se a necessidade de divisão do modelo entre estes. Os efeitos marginais e os testes- $t$ para as variáveis do modelo de migração apenas para as mulheres, estão na Tabela 8 . 
Tabela 8. Modelo próbite de determinação da migração interna brasileira para o ano de 1998 apenas para mulheres

\begin{tabular}{|c|c|}
\hline Variáveis & MIGRANTE \\
\hline \multirow{2}{*}{ CONSTANTE } & $-0,37273$ \\
\hline & $(-11,31)^{* * *}$ \\
\hline \multirow[t]{2}{*}{ AMARELA } & 0,17254 \\
\hline & $(6,98)^{* * *}$ \\
\hline \multirow[t]{2}{*}{ PARDA } & $-0,00759$ \\
\hline & $(-1,87)^{*}$ \\
\hline \multirow[t]{2}{*}{ NEGRA } & $-0,06880$ \\
\hline & $(-8,74)^{* * *}$ \\
\hline EDU2 & $\begin{array}{c}0,01731 \\
(2,58)^{* * *}\end{array}$ \\
\hline EDU3 & $\begin{array}{c}\mathbf{0 , 0 3 2 7 2} \\
(5,39)^{* * *}\end{array}$ \\
\hline EDU4 & $\begin{array}{c}0,01913 \\
(2,63)^{\star * *}\end{array}$ \\
\hline \multirow[t]{2}{*}{ EDU5 } & $-0,04911$ \\
\hline & $(-7,08)^{* * *}$ \\
\hline \multirow[t]{2}{*}{ EDU6 } & $-0,09314$ \\
\hline & $(-10,06)^{* * *}$ \\
\hline \multirow[t]{2}{*}{ IDADE } & 0,01852 \\
\hline & $(11,15)^{* * *}$ \\
\hline IDADE2 & $\begin{array}{l}-0,00016 \\
(-8,29)^{* * *}\end{array}$ \\
\hline \multirow[t]{2}{*}{ TAMANHO } & $-0,00853$ \\
\hline & $(-7,25)^{* * *}$ \\
\hline \multirow[t]{2}{*}{ RENDCAP } & 0,00002 \\
\hline & $(7,62)^{* * *}$ \\
\hline Número de observações & 76.017 \\
\hline Número de Migrantes & 43.130 \\
\hline $\begin{array}{l}\text { Teste da razão de } \\
\text { verossimilhança }\end{array}$ & $794,92 * * *$ \\
\hline
\end{tabular}

As estatísticas $-t$ são dadas entre parênteses abaixo dos efeitos marginais

*Significativo ao nível de $10 \%$

**Significativo ao nivel de $5 \%$

***Significativo ao nivel de $1 \%$ 
Baseado no teste da razão de verossimilhança que apresentou valor igual a 794,92, o modelo de migração para mulheres é altamente relevante, rejeitando a hipótese nula do modelo não possuir poder explicativo.

Todas as variáveis relacionadas no modelo foram estatisticamente significantes na determinação da migração interna. A variável Parda, que anteriormente foi não estatisticamente significante, apresentou-se significante ao nível de $10 \%$. Todas as outras foram significantes ao nível de $1 \%$.

O coeficiente da variável Amarela apresentou sinal positivo, indicando que as mulheres amarelas são mais propensas à migração do que as brancas. Sinal contrário foi observado nos coeficientes das variáveis Parda e Negra, que relata que as mulheres brancas possuem 0,75 e 6,88 pontos percentuais maior probabilidade à migração do que as pardas e negras, respectivamente.

Analisando as variáveis binárias para os grupos de escolaridade, assim como o modelo anterior, tem-se que apenas os coeficientes das variáveis EDU5 e EDU6 apresentaram sinal negativo. Assim, as mulheres que possuem de 1 a 3 anos de estudo, de 4 a 7 anos de estudo e de 8 a 10 anos de estudo possuem, respectivamente, 1,73, 3,27 e 1,91 pontos percentuais maior probabilidade de deixar seu local de origem do que aquelas mulheres que possuem menos de 1 ano de estudo. Semelhante ao modelo anterior, ao completarem 11 anos de estudo, o aumento da escolaridade não interfere positivamente na decisão da mulher migrar.

O coeficiente estimado para a variável Idade apresentou sinal positivo e de idade ao quadrado negativo, indicando que a probabilidade das mulheres migrarem aumenta até que estas atinjam, aproximadamente, 58 anos e depois começa a declinar.

Já o coeficiente da variável que representa o número de componentes da família, Tamanho, apresentou sinal negativo, indicando que, quanto maior o número de 
componentes da família, menor a probabilidade da mulher desta família migrar. Assim, como resultado, tem-se que à medida que ocorre um aumento de 10 componentes na sua família, decresce em 8,53 pontos percentuais a probabilidade desta mulher migrar.

Para finalizar, o coeficiente da variável Rendcap, que indica a renda per capita mensal, assim como o modelo que inclui tanto os homens quanto as mulheres na análise, apresentou sinal positivo, indicando que um aumento de $\mathrm{R} \$ 1.000 \mathrm{em}$ sua renda per capita acresce a probabilidade em 2,64 pontos percentuais da mulher deixar seu local de origem.

$\mathrm{O}$ modelo que exclui as mulheres no processo de migrações internas e aborda apenas características migratórias dos homens, também utiliza as mesmas variáveis anteriormente analisadas e apresenta resultados bastante semelhantes àqueles obtidos no modelo que inclui ambos os sexos. Os efeitos marginais e os testes- $t$ para as variáveis estão dispostos na Tabela 9. 
Tabela 9. Modelo próbite de determinação da migração interna brasileira para o ano de 1998 apenas para homens

\begin{tabular}{|c|c|}
\hline Variáveis & MIGRANTE \\
\hline \multirow[t]{2}{*}{ CONSTANTE } & $-0,49393$ \\
\hline & $(-14,24)^{* * *}$ \\
\hline \multirow[t]{2}{*}{ AMARELA } & 0,14466 \\
\hline & $(5,76)^{* * *}$ \\
\hline \multirow[t]{2}{*}{ PARDA } & 0,00784 \\
\hline & $(1,84)^{*}$ \\
\hline \multirow[t]{2}{*}{ NEGRA } & $-0,04201$ \\
\hline & $(-5,22)^{* * *}$ \\
\hline EDU2 & $\begin{array}{c}0,04481 \\
(6.53)^{* * *}\end{array}$ \\
\hline EDU3 & $\begin{array}{c}0,08173 \\
(13,27)^{* * *}\end{array}$ \\
\hline EDU4 & $\begin{array}{c}0,07080 \\
(9,60)^{\star * *}\end{array}$ \\
\hline \multirow[t]{2}{*}{ EDU5 } & 0,02217 \\
\hline & $(3,07)^{* * *}$ \\
\hline \multirow[t]{2}{*}{ EDU6 } & 0,01536 \\
\hline & $(1,58)$ \\
\hline \multirow[t]{2}{*}{ IDADE } & 0,01957 \\
\hline & $(11,27)^{* * *}$ \\
\hline IDADE2 & $\begin{array}{c}-0,00015 \\
(-7,40)^{* * *}\end{array}$ \\
\hline \multirow[t]{2}{*}{ TAMANHO } & $-0,00965$ \\
\hline & $(-8,12)^{* * *}$ \\
\hline \multirow[t]{2}{*}{ RENDCAP } & 0,00002 \\
\hline & $(6,49)^{* * *}$ \\
\hline Número de observações & 69.492 \\
\hline Número de Migrantes & 38.572 \\
\hline $\begin{array}{l}\text { Teste da razão de } \\
\text { verossimilhança }\end{array}$ & $1168,93^{* * *}$ \\
\hline
\end{tabular}

As estatísticas $-t$ são dadas entre parênteses abaixo dos efeitos marginais

*Significativo ao nivel de $10 \%$

** Significativo ao nível de $5 \%$

***Significativo ao nivel de $1 \%$ 
O teste de razão de verossimilhança para o modelo que inclui apenas os homens brasileiros, apresentou valor igual a $1.168,93$, altamente significativo, rejeitando a hipótese nula do modelo não possuir valor explicativo para o fenômeno estudado.

Assim como o modelo que exclui a participação dos homens, todas variáveis relacionadas foram estatisticamente significantes na determinação da migração interna, excluindo apenas a variável EDU6. Apenas a variável Parda apresentou nível de significância $10 \%$, todas as outras variáveis apresentaram nível de significância igual a $1 \%$.

Os sinais esperados para os coeficientes das variáveis estudadas foram semelhantes àqueles encontrados pelo modelo que aborda apenas a participação das mulheres, excluindo apenas o coeficiente da variável EDU5 que passou a apresentar sinal positivo.

O coeficiente estimado para a variável Amarela e Parda apresentaram valores positivos, indicando que os homens amarelos e pardos possuem, respectivamente, 14,46 e 0,78 pontos percentuais maior probabilidade de migrar do que os homens brancos. Já a variável Negra apresentou sinal negativo, relatando que os homens negros possuem 4,20 por cento menor propensão a migrar do que os brancos. Comparativamente ao modelo que exclui os homens da análise, tem-se que os homens pardos apresentam maior probabilidade à migração que os brancos, enquanto que as mulheres brancas são mais propensas a migrar do que as pardas.

Analisando as variáveis binárias para os grupos de escolaridade, tem-se que todos os coeficientes estimados apresentaram sinais positivos. Assim, os homens que possuem de 1 a 3 anos de estudo, de 4 a 7 anos de estudo, de 8 a 10 anos de estudo e de 11 a 14 anos de estudo possuem, respectivamente, 4,48, 8,17, 7,08 e 2,21 pontos percentuais maior probabilidade de migrar do que aqueles que possuem menos de 1 ano de estudo. 
Comparativamente ao modelo que aborda apenas o sexo feminino, tem-se que, à medida que aumenta o grau de instrução dos homens, aumenta a propensão destes deixarem seu local de origem, enquanto que as mulheres apresentam apenas este resultado até atingirem 11 anos de estudo. Ao completarem aproximadamente o segundo grau, o aumento da escolaridade não interfere negativamente na decisão da mulher brasileira migrar. Assim, a mulher que atinge o segundo grau e nível superior migra menos do que as sem instrução, enquanto que o homem está sempre disposto e propenso a migrar, mesmo em níveis altos de escolaridade.

Como o resultado obtido para mulheres, o coeficiente estimado para a variável Idade apresentou sinal positivo e idade ao quadrado negativo, indicando que a probabilidade dos homens migrarem aumenta até, aproximadamente, 65 anos e depois diminui com o aumento da idade.

O sinal negativo encontrado para o coeficiente estimado da variável Tamanho indica que assim como as mulheres, quanto maior o número de componentes da família menor a probabilidade do homem desta família migrar. De acordo com o resultado encontrado, um acréscimo de 10 componentes na sua família faz com que o homem possua 9,65 por cento menor probabilidade de deixar seu local de origem, aproximadamente, 1 por cento menor probabilidade comparativamente às mulheres.

Por último, tem-se que o sinal encontrado para o coeficiente da variável Rendcap apresentou positivo, indicando que um aumento de $\mathrm{R} \$ 1.000 \mathrm{em}$ sua renda, faz com que o indivíduo obtenha mais recursos para financiar sua migração e acresce em 2,30 pontos percentuais a probabilidade deste homem deixar seu local de origem e migrar. Este valor encontrado para a variável Rendcap pelo modelo que inclui apenas os homens, é bastante semelhante ao obtido pelo modelo que exclui os homens da análise, que apresenta um acréscimo de 2,64 pontos percentuais na probabilidade da mulher migrar. 


\section{CONCLUSÃo}

O fenômeno migratório interno brasileiro, apesar de ainda ser bastante intenso, apresenta declínio nos últimos anos. A participação de migrantes na população total brasileira declinou de 40,5 pontos percentuais em 1993 para 39,2 pontos percentuais em 1998. Esta tendência dos movimentos migratórios pode ser observada tanto nos deslocamentos urbanos-urbanos quanto nos rurais-urbanos.

A migração continua grande, mas o ritmo mais lento significa que se desarmou o gatilho da bomba populacional que se dirigia aos grandes centros com expectativa de uma vida melhor. Seja por motivos da violência que ameaça a população como um todo, ou ainda, pela falta de perspectiva de emprego, a população brasileira não está tão disposta a deixar seu local de origem e migrar. No campo, o aumento de oportunidades e empregos fora da atividade agrícola reduz o ritmo do êxodo rural. Hoje, quatro em cada dez trabalhadores adultos nas áreas rurais preferem trabalhar em atividades não-agrícolas a migrar.

Em termos regionais, os estados que compõem a região Nordeste são aqueles que ainda apresentam um fluxo significativo de migrantes para outros estados, ou seja, apesar de grandes modificações ocorridas no processo migratório brasileiro desde seu início, a região Nordeste permanece sendo o grande pólo brasileiro de repulsão de população. Em contrapartida, a região Sudeste apresenta fatores que levam indivíduos de todo o país a migrarem em sua direção. 
Pode-se dizer que os deslocamentos migratónios ocorrem devido, principalmente, a decisões tomadas pelo indivíduo em resposta a fatores econômicos, sociais e culturais, que assumem formas diferenciadas nos locais de origem e de destino. Assim, ao se conhecer os principais focos migratórios brasileiros e as causas que levam a esta migração interna, torna-se possível a aplicação de políticas migratórias diferenciadas para regiões de atração e expulsão, a fim de minimizar os problemas causados pelo fenômeno migratório.

Hoje, observa-se uma mudança não só na intensidade dos fluxos migratórios internos brasileiros, mas também no perfil e características dos migrantes. A probabilidade migratória brasileira, definida pelo atual trabalho, cresce à medida que o indivíduo apresenta ser mulher, com a estrutura etária mais envelhecida, com alto nível de escolaridade, com número pequeno de componentes na família e com alta renda per capita.

Comparativamente com décadas anteriores, tem-se que, hoje, ocorre um destaque no deslocamento das populações mais envelhecidas, em conseqüência de alterações no perfil demográfico da população brasileira nos últimos anos. O que mais chama atenção, é que, como hoje em dia a conquista de um novo emprego e a adaptação em uma nova cidade são obstáculos mais evidentes comparativamente a décadas passadas, os fluxos migratórios internos brasileiros vêm ganhando bastante participação das classes mais favorecidas da população, ou seja, os movimentos que anteriormente eram marcados pela condição de pobreza passaram a mesclar-se com fluxos migratórios de população de renda média e alta. Atualmente, à medida que o indivíduo possui maior renda, também adquire maior potencial de deixar seu local de residência e migrar.

Para finalizar, ao contrário das bibliografias já desenvolvidas, o atual estudo conclui que não só variáveis econômicas devem ser consideradas ao se estudar o fenômeno migratório interno brasileiro. Variáveis consideradas não econômicas, como 
sexo, cor ou raça, escolaridade e tamanho da família mostraram-se bastante relevantes e importantes ao se estudar as características destes movimentos e seus determinantes. 


\section{REFERÊNCIAS BIBLIOGRÁFICAS}

ABRAMOVAY, R.; CAMARANO, A. A. Êxodo rural, envelhecimento e masculinização no Brasil: Panorama dos últimos 50 anos. Rio de Janeiro: IPEA, Jan. 1999, p.23 (Texto para Discussão, 621).

ALBUQUERQUE, R. C., (coord). O Brasil social: realidades, desafios, opções. Rio de Janeiro: IPEA, 1993, (Série IPEA, 139).

ANDRADE, G. O. Migrações internas e o Recife. Recife: Instituto Joaquim Nabuco de Pesquisas Sociais, 1979, p.100, (Série Estudos e Pesquisas, v. 12).

ARAÚJO, H; RAMOS, C. A. Fluxos Migratórios, Desemprego e Diferenciais de Renda. Rio de Janeiro: IPEA, Jul. 1999, (Texto para Discussão, 657).

BALÀN, J. Urbanización, migraciones internas y desarrollo regional, notas para discusión. In: Migrações internas e desenvolvimento regional. Belo Horizonte: 1973, p. 301-26.

BARROS, R. P.; MENDONÇA, R. S. P. Investimentos em Educação e Desenvolvimento Econômico. Rio de Janeiro: IPEA, Nov. 1997, p.7, (Texto para Discussão, 525).

BEHRMAN, J. R.; DURYEA, D.; SZÉKELY, M. Schooling Investiments and Aggregate Conditions: a household - survey - based approach for Latin America and The Caribbean. Journal of Political Economy. Chicago: Nov. 1999.

CAMARgo, J. F. C. A Cidade e o Campo: o êxodo rural no Brasil. Rio de Janeiro: Universidade de São Paulo, 1968, p.115, (Coleção Buriti, v. 20).

COSTA, M. A. Migrações internas no Brasil. Rio de Janeiro: IPEA/INPES, 1971, p.190, (Monografia, n. 5). 
FILHO, S. B. H. Migrações internas e a distribuição regional da renda: $1970-1980$. Estudos Econômicos, v.19, n.3, p. 389-416, Set/Out. 1989.

GRAHAM, D. H; HOLANDA FILHO, S. B. Inter-regional and urban migration and economic growth in Brazil. IN: UNIVERSIDADE FEDERAL DE MINAS GERAIS. Migrações internas e desenvolvimento regional, v.1, Belo Horizonte: CEDEPLAR, 1973 , p. $327-76$.

GRAHAM, D. H. Padrões de convergência e divergência do crescimento econômico regional e das migrações no Brasil: 1940/1960. Revista Brasileira de Economia, Rio de janeiro: v. 23, n. 3, p. 53-76, Jul/Set. 1969.

HARRIS, J. R; TODARO, M. P. Migration, unemployment and development: two sector analysis. American Economic Review, v.15,p.126-42, Mar. 1970.

JUDGE, G. G. et alii. Introduction to the theory and practic of econometrics. 2.ed, John Wiley \& Sons, 1988, p.1024.

KALUZNY, R., Determinants of household migration: A comparative study by race and povety level. Review of Economics ans Statistics, v. 57, n. 3, p. 269-74, Aug. 1975.

LEE, Everete S. A Theory on migration. Demografy. (Series in Studies of Human Resources, 1),v. 3, n.1, p. 47-57, 1966. Apresentado na reunião Anual da Associação Histórica do Vale do Mississipi, Cidade Kansas, Abr. 1965 - Resumo.

MARTINE, G.; CAMARGO, L. Crescimento e distribuição da população brasileira: tendências recentes. Revista Brasileira de Estudos de População, v. 1, n. 112, p. 99-144, Jan./Dez. 1984.

MATA, Milton da. Urbanização e migrações internas. Pesquisa e Planejamento Econômico. Rio de Janeiro:, v.3, n: 3, p. 715-46, Out. 1973.

MATA, M.; CARVALHO, E. W. R.; SILVA, M. T. C. Migrações internas no Brasil: aspectos econômicos e demográficos. Rio de Janeiro: IPEA, 1973, p.217, (Coleção Relatórios de Pesquisa, 19).

NAKOSTEEN, R.; ZIMMER, M. Migration and income: the question of self-selection. Southern Economic Journal, v. 46, p. 840-851, 1980.

PATARRA, N.; BAENINGER, R.; BÓGUS, L. M. M.; JANNUZZI, P.M. Migração, condições de vida e dinâmica urbana: São Paulo 1980/1993. Campinas, UNICAMP, Instituto de Economia, 1997, p. 574.

PESQUISA NACIONAL POR AMOSTRA DE DOMÍCíl IOS - CD ROM.Rio de Janeiro: Fundação Instituto Brasileiro de Geografia e Estatística., 1998, 
RAVENSTEIN, E. G. The Laws of migration. Journal of the satatistical society. v. 47 , pt. 1, p. 167-227, June 1885 .

SAHOTA, G. S. An economic analysis of internal migration in Brazil. Journal of Political Economy. Chicago: v. 76, p. 218-245, Mar/Apr. 1968.

SJAASTAD, L. A. The cost and returns of human migration. Journal of Political Economy. Chicago: v. 70, p. 80-93, Oct. 1962,.

TODARO, M. P. A Model of labor migration in less developed countries. The American Economic Review. v. 59, n. 1, p.138-48, Mar. 1969.

TODARO, M. P. Income expectations, rural-urban migration and employment in Africa. International Labour Review. v. 104, n. 5, Nov. 1971.

VANDERKAMP, J., Migration flows, their determinants and the effects of return migration. Journal of Political Economy. v. 79, n. 5, p.1012-31, Sept-Oct. 1971,.

WERTHEIN, J.; BORDENAVE J. D. Educação rural no Terceiro Mundo: experiências e novas alternativas. Rio de Janeiro: Paz e Terra, 1981.

WORLD DEVELOPMENT REPORT. Oxford: The World Bank, 1990, p.260.

ZHAO, Yaohui. Labor migration and earnings differences: The case of rural China. America Economic Review. v. 47, Iss. 4, p. 767-782, Jul. 1999. 